\title{
Effects of hearing loss on traffic safety and mobility
}

\author{
Birgitta Thorslund
}

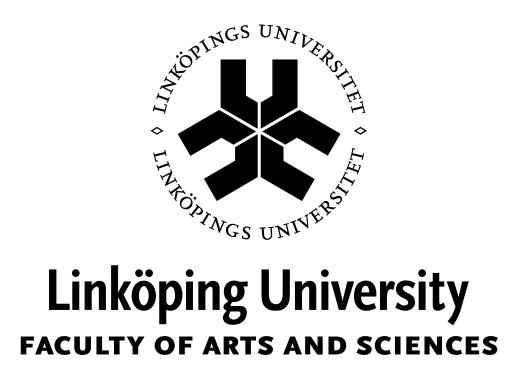

Linköping Studies in Arts and Science No. 636

Studies from the Swedish Institute for Disability Research No. 69

Department of Behavioural Sciences and Learning

Linköping 2014 
Linköping Studies in Arts and Science $\cdot$ No. 636

At the Faculty of Arts and Sciences at Linköping University, research and doctoral studies are carried out within broad problem areas. Research is organized in interdisciplinary research environments and doctoral studies mainly in graduate schools. Jointly, they publish the series Linköping Studies in arts and Science. This thesis comes from the Swedish Institute for Disability Research at the Department of Behavioural Sciences and Learning.

Distributed by:

Department of Behavioural Sciences and Learning

Linköping University

58183 Linköping

Sweden

Birgitta Thorslund

Effects of hearing loss on traffic safety and mobility

Edition 1:1

ISBN 978-91-7519-178-2

ISSN 0282-9800

ISSN 1650-1128

CBirgitta Thorslund

Department of Behavioural Sciences and Learning, 2014

Cover illustration by: Tobias, Tyra, and Bruno Thorslund

Printed by: LiU-Tryck, Linköping 2014 


\section{Abstract}

Research into the effect of hearing loss (HL) on traffic safety and mobility is limited and the empirical findings are somewhat inconsistent. HL is one of the most frequent sensory deficits in humans, leading to loss of auditory information, which may affect behavior in traffic situations and might reduce traffic safety and mobility. The prevalence of age-related HL in Europe is roughly 30\% for men and $20 \%$ for women at the age of 70 years, and $55 \%$ for men and $45 \%$ for women at the age of 80 years. The prevalence of age-related HL is increasing, and as a consequence the number of road users with HL will also increase.

The aim of this $\mathrm{PhD}$ thesis was to investigate traffic safety and mobility for individuals with HL. Three studies were conducted: 1. a questionnaire survey aimed to evaluate differences in choice of transportation that might be related to HL, 2. a driving simulator study that looked into compensatory strategies and evaluated the efficiency of a tactile signal to alert the driver, and 3. a field study to evaluate these effects in real traffic and to evaluate a navigation system with a supportive tactile signal.

The results of the three studies indicate that there are effects of HL on traffic safety and mobility. The effects are relatively small and often bound to driving complexity; but, systematic and consistent in replicated studies. Differences in transportation habits related to HL include less likelihood of having a driver's license and a higher valuing of written information, with the latter possibly prioritized before time and safety issues. Moreover, respondents with more HL were less concerned about the effects of HL, which suggests that they might be using compensatory strategies.

In the experimental studies, differences in driving behavior related to $\mathrm{HL}$ were bound to driving conditions and occurred when the complexity of the driving task increased. There was also an effect of HL on visual behavior, indicated in the simulator and confirmed in the field study, suggesting that drivers with HL have more active visual behaviors with more frequent glances in the rear-view mirror and a general scanning of the environment before looking away from the road. A tactile signal in the driver seat was found useful in both experimental studies, both for calling for the driver's attention and facilitating navigation using a GPS navigation device.

It was concluded that there are effects of HL on both traffic safety and mobility, consistently pointing toward a generally more cautious driving behavior with the use of both compensatory and coping strategies, which suggests a difference in experienced safety. Compensatory strategies associated with HL include driving at lower speeds and using a more comprehensive visual search behavior. Coping strategies associated with HL include engaging less in 
distracting activities. Evaluation of the tactile signal suggests that it may make driver assistance systems more accessible, not only to drivers with HL, but to all drivers. At the same time, the systems might become more effective for all users, since visual resources can be more focused on the road, which could increase both traffic safety and mobility in general. 


\section{List of papers}

\section{Paper I}

Thorslund, B., Peters, B., Lyxell, B., \& Lidestam, B. (2013). The Influence of Hearing Loss on Transport Safety and Mobility. European Transport Research Review, 5(3), 117-127.

\section{Paper II}

Thorslund, B., Peters, B., Lidestam, B., \& Lyxell, B. (2013). Cognitive workload and driving behavior in persons with hearing loss. Submitted to Transportation Research Part F: Traffic Psychology and Behaviour, 21, 113-121.

\section{Paper III}

Thorslund, B., Ahlström, C., Peters, B., Eriksson, O., Lyxell, B., \& Lidestam, B. (2014, May 29). Cognitive workload and visual behavior in elderly persons with hearing loss. European Transport Research Review, published online first, 19. doi:10.1007/s12544-014-0139-z

\section{Paper IV}

Thorslund, B., Peters, B., Herbert, N., Holmqvist, K., Lidestam, B., Black, A., Lyxell, B. (2013). Hearing loss and a supportive tactile signal in a navigation system: Effects on driving behavior and eye movements. Journal of Eye Movement Research, 6(5), 1-9. 



\section{Table of Contents}

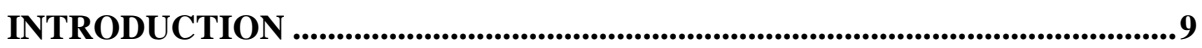

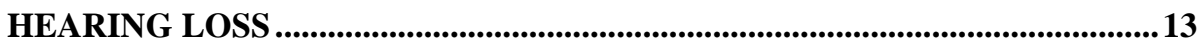

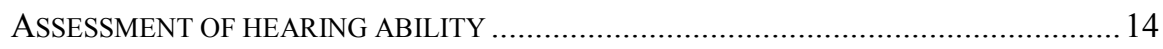

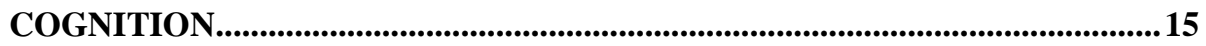

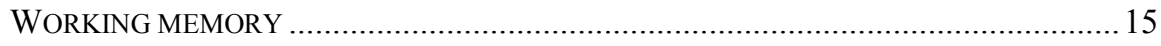

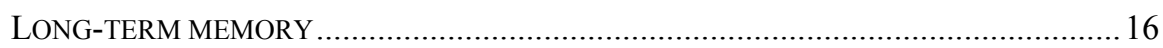

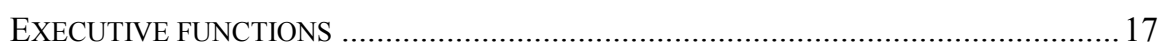

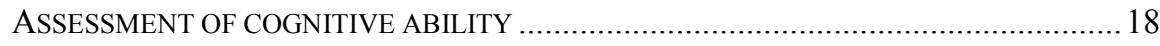

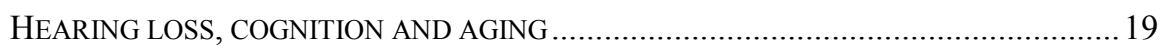

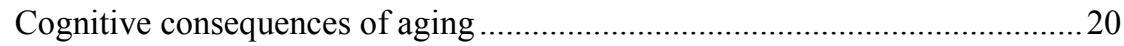

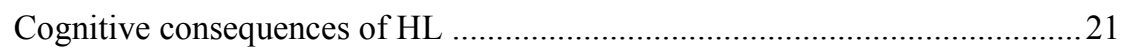

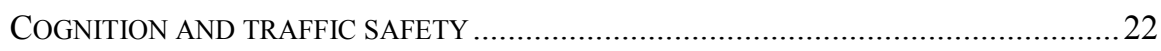

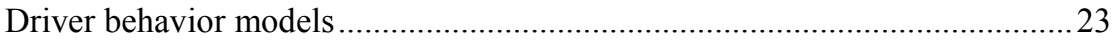

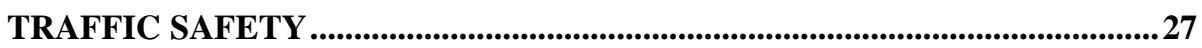

MOBILITY AND QUALITY OF LIFE ................................................................... 28

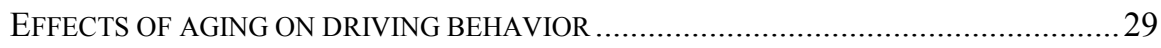

ASSESSMENT OF DRIVER BEHAVIOR ................................................................... 30

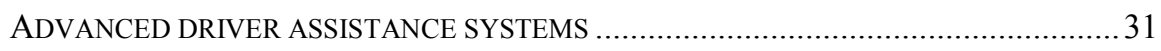

GENERAL AIM AND RESEARCH QUESTIONS............................................33

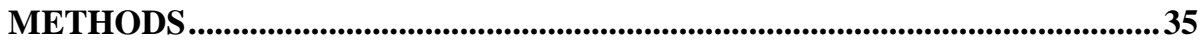

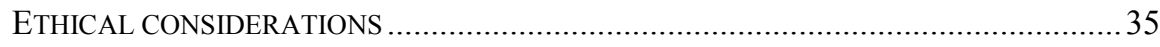

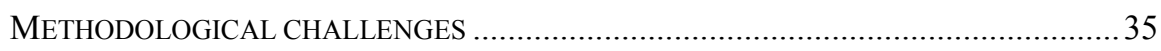

HL population and recruitment of participants .............................................. 35

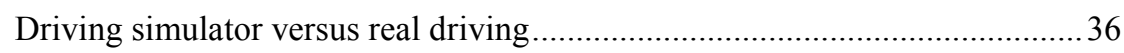

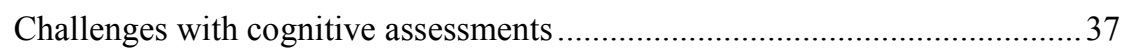

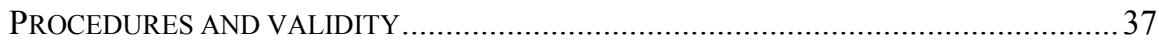

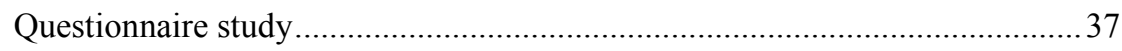

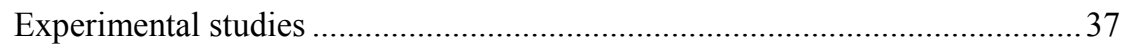

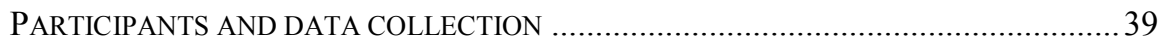

DESIGN AND STATISTICAL ANALYSES .......................................................... 40

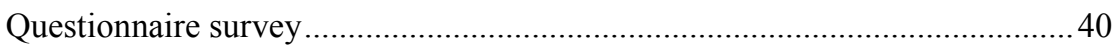




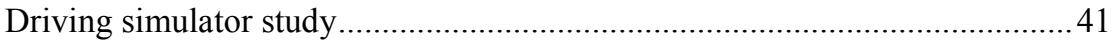

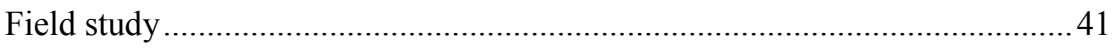

SUMMARY OF STUDIES AND PAPERS ....................................................43

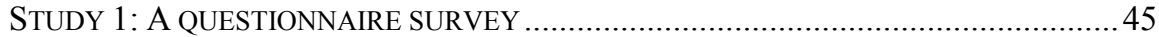

Paper I: The influence of hearing loss on transport safety and mobility ..........45

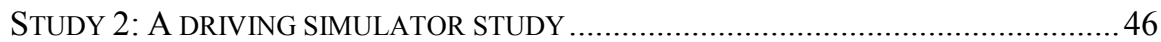

Paper II: Cognitive workload and driving behavior in persons with hearing

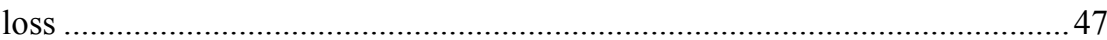

Paper III: Cognitive workload and visual behavior in elderly drivers with

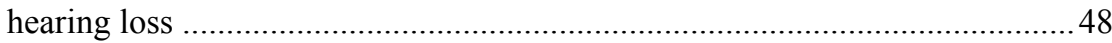

STUDY 3: A FIELD STUDY IN REAL TRAFFIC................................................... 50

Paper IV: Hearing loss and a supportive tactile signal in a navigation system: effects on driving behavior and eye movements ..............................50

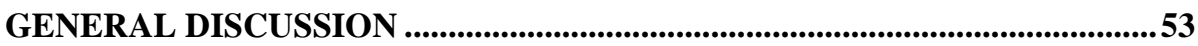

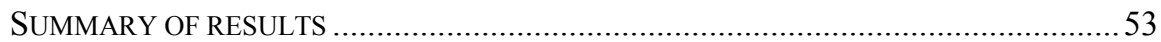

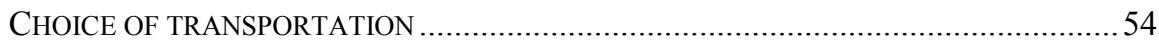

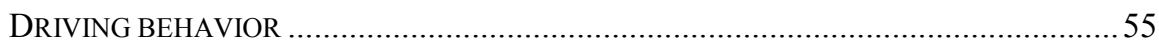

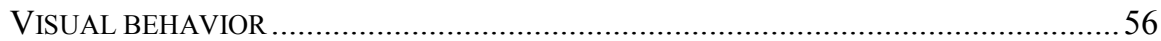

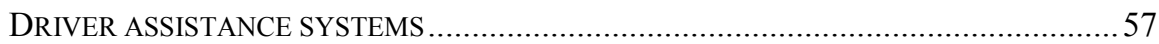

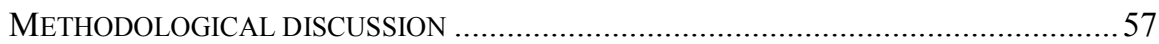

CONCLUSIONS

SUGGESTIONS FOR FUTURE RESEARCH ................................................61

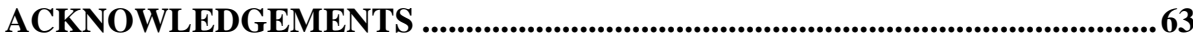

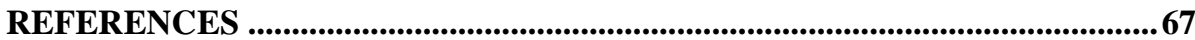

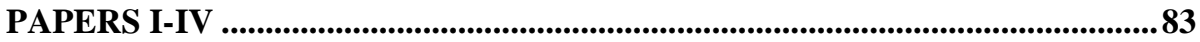




\section{List of abbreviations}

ADAS Advanced driver assistance system

CDT Clock-drawing test

EF Executive function

HL Hearing loss

HMI Human machine interaction

HRF Swedish Association for Hard of Hearing People

ICF International Classification of Functioning, Disability and Health

LTM Long-term memory

MCZ Multiple comfort zone model

NH Normal hearing

OR Odds ratio

PTA Pure tone average

RAT Risk allostasis theory

RHM Risk homeostasis model

RMM Risk monitor model

TDH Task difficult homeostasis

TIPS Text information processing system

TMT Trail making test

UFOV Useful field of view

WHO World Health Organization

WM Working memory 


\section{List of concepts and definitions}

Age-related HL Presbycusis

Compensatory strategies

Coping strategies

Mobility

Older adults
The most common type of HL typically starting around middle adulthood and then progressing, particularly affecting the high frequency ranges.

Efforts made by the individual (consciously or unconsciously) to maintain a given level of functioning despite decline in, or loss of, previously available resources

Use of conscious effort to solve personal and interpersonal problems and to seek to master, minimize, or tolerate stress or conflict.

The quality or state of being mobile. The ability to move freely.

Individuals over 65 years 


\section{Introduction}

For many people transportation is a part of everyday life and is so established that we do not think about how complex even the simplest task really is. Being a road user demands cognitive skills in order to assemble new information in the traffic environment, apply it to stored knowledge, and make decisions. This thesis examines the travel habits and driving behaviors of individuals with hearing loss (HL) and how cognitive skills interact with their driving behavior. Driving a car is a cognitively initiated and controlled task, and thus one approach to understand driving behavior is to examine how cognitive skills are involved. Cognitive psychology is the area that describes the internal processes involved in making sense of the environment and deciding what action might be appropriate (Eysenck \& Keane, 2010; Neisser, 1976).

$\mathrm{HL}$ is one of the most frequent sensory deficits in humans, with a prevalence of approximately $10 \%$ in the general population in the western world, and it is a common chronic condition among the elderly (Stevens et al., 2013). HL entails a loss of auditory information, which may affect behavior in traffic and might reduce traffic safety. Research into the effect of HL on traffic safety and mobility is limited and the empirical findings are somewhat inconsistent. From a legal perspective, based on this relatively low level of knowledge, HL is not considered an increased traffic safety risk (Englund, 2001; Glad, 1977), and therefore hearing is not required for obtaining a driver's license for passenger cars.

From a safety perspective, some studies suggest an association between HL and increased risks of traffic accidents (Ivers, Mitchell, \& Cumming, 1999; Picard et al., 2008). However, other studies show no such relation (Green, McGwin, \& Owsley, 2013; McCloskey, Koepsell, Wolf, \& Buchner, 1994). Schmolz (1987) examined the importance of hearing for road users and found that HL is associated with a higher degree of inattention. With regard to attention, Hickson et al. (2012) showed that HL in older drivers was associated with poorer driving performance in the presence of distraction, but not without distraction. On the other hand, Picard et al. (2008) suggested that HL leads to a reduction in speeding violations, probably due to self-regulation. In sum, the effect of HL on traffic safety remains mostly unknown, and possibly connected 
to specific situations; although its associations with attention and driving speed have been shown.

From a mobility perspective, it is possible that of HL leads to self-regulation due to feelings of unsafety. This is an important aspect to consider, because mobility is important for quality of life (Farquhar, 1995), often connected to factors such as psychological well-being and independence (Bonnel, 1999; Fonda, Wallace, \& Herzog, 2001; Gabriel \& Bowling, 2004; Marottoli et al., 1997), and also associated with higher life satisfaction (Banister \& Bowling, 2004; Hakamies-Blomqvist \& Wahlström, 1998 Gagliardi, Marcellini, Papa, Giuli, \& Mollenkopf, 2010).

Physiologically, disruption of any part along the auditory pathway (central to peripheral) may lead to HL and there are two main diagnoses. Problems in the outer ear (such as blockage of the ear canal) or middle ear (such as ossicular chain discontinuity) cause conductive hearing loss, and problems in the inner ear (such as loss of outer or inner hair cells in the cochlea) or problems in the auditory nerve leading to the central auditory pathway (such as auditory neuropathy) can result in sensorineural HL (Arlinger, 2007).

This thesis is focused on age-related HL, also known as presbycusis. This is the most common type of HL typically starting around middle adulthood and progressing, affecting the high frequency ranges particularly (Pearson et al., 1995; Schneider, Pichora-Fuller, \& Daneman, 2010) and inducing distortion (Moore, 1995). The prevalence of age-related HL in Europe is roughly 30\% for men and $20 \%$ for women at the age of 70 years, and $55 \%$ for men and $45 \%$ for women at the age of 80 years (Roth, Hanebuth, \& Probst, 2001). The prevalence of age-related HL is increasing, due to populations becoming progressively older and thus presenting symptoms of reduced sensory function. A consequence of the increasing prevalence of HL is that the number of road users (not only drivers) with HL will also increase. This certainly leads to an increased need of knowledge about these individuals with regard to traffic safety and mobility.

Hearing is important for our sense of spatial orientation and temporal resolution and thus of high relevance for traffic safety. Sounds behind us provide information about events that it not possible to see and we receive information about positions and distances. Most frequency spectra of exterior tires or road noise display a prominent peak in the range of 700-1300 Hz (Sandberg, 2003). Since the noise from cars driving on roads is mainly in low frequencies, i.e. with low-pitched sounds (Wu, Stangl, Bentler, \& Stanziola, 2013), individuals with presbycusis should be able to hear these specific sounds rather well. However, there might be other vital auditory input in high frequencies (e.g. a bicycle bell can be hard to hear for a pedestrian), which is partly or totally missed, and may therefore lead to loss of critical information for the listener. Distortion leads to 
increased difficulties in hearing masked sounds, in other words low frequency traffic noise can mask high frequency sounds. Research on effective siren characteristics suggest either a sufficiently loud, wide frequency spectrum (1-4 $\mathrm{kHz}$ ) to overcome masking noise (De Lorenzo \& Eilers, 1991; Catchpole \& McKeown, 2007) or sirens that broadcast low frequencies so that the siren sound can penetrate into vehicle cabins (Howard et al., 2011). Furthermore, the use of in-vehicle systems for information, support, and navigation is rapidly increasing. These systems often use auditory signals that may not be accessible to drivers with HL. Thus, investigating other modalities such as light or vibration should be considered to also make these systems accessible to drivers with HL.

In the present thesis, traffic safety and mobility for individuals with HL is examined from the perspective of cognitive psychology. That is, how different cognitive skills in combination with HL affect traffic safety and mobility. Focus is on the intersection between three research areas: audiology, cognition, and traffic safety. The background and central expressions of these areas and their interrelations with each other and with age are presented in the following chapters. Figure 1 presents an overview of the thesis in terms of what is covered or excluded in each area, as well as in the intersection between them.

\section{Audiology \\ Hearing Loss: \\ - Prevalence \\ - Classifications \\ - Consequences \\ - Presbycusis \\ - Communication \\ Acoustics \\ Anatomy \\ Physiology \\ Genetics \\ Tinnitus}

\section{Effects of HL on traffic safety and mobility from a}

\section{cognitive perspective}

Cognition and driving

Compensatory strategies

Self-regulation and driving cessation

Driver behavior models

Cognitive consequences of $\mathrm{HL}$ relevant for traffic safety

Interactions with aging

Figure 1: Overview of the thesis. The three main topics are Traffic Safety, Audiology and Cognition. These are presented and discussed separately, in relation to each other and in relation to age. Concepts included in the thesis are listed in black and terms excluded or mentioned only briefly are listed in white. 


\section{Hearing loss}

The International Classification of Functioning, Disability and Health (ICF) suggested by the World Health Organization (WHO) is a framework based on the biopsychosocial model that describes the consequences of a particular health condition or disability in terms of various levels of disablement and functioning (WHO, 2001). These may include body functions on the organic level, activities on the personal level, and participation on the social level. These levels also interact with each other and may be further influenced by personal and environmental factors. Thus, it is important to understand the consequences of a particular health condition or disability from multiple perspectives (Rimmer, 2006).

According to the ICF, functioning and disability are typically conceptualized as a complex interaction between an individual's health condition, contextual factors of the environment, and personal factors (WHO, 2001). The consequences of HL include the inability to interpret speech sounds, often producing a reduced ability to communicate, delay in language acquisition in children, economic and educational disadvantage, social isolation, and stigmatization. This may also be worsened by some medical conditions such as diabetes (Mathers, Smith, \& Concha, 2003).

The degree of HL is categorized according to the better ear hearing level averaged over the frequencies of $0.5,1,2$, and $4 \mathrm{kHz}$ and divided into mild (26$40 \mathrm{~dB})$, moderate $(41-60 \mathrm{~dB})$, severe $(61-80 \mathrm{~dB})$, and profound (>80 dB) (Mathers, et al., 2003). Individuals with a HL of $95 \mathrm{~dB}$ or more are commonly referred to as deaf.

Age-related HL, the focus of this thesis, originates with the deterioration of auditory function and is part of normal aging, usually starting in the middle adulthood (Pearson et al., 1995; Schneider, Pichora-Fuller, \& Daneman, 2010). Outer hair-cell damage, degeneration of the stria vascularis (producing endocochlear potential) and the auditory nerve are the main causes (PichoraFuller \& Singh, 2006), and auditory processes, such as temporal resolution and duration discrimination, are negatively affected (Fitzgibbons \& Gordon-Salant, 2010; Saremi \& Stenfelt, 2013). 


\section{Assessment of hearing ability}

Assessment of hearing ability is performed either psychoacoustically with an active listener (e.g., tone audiometry) or by objective methods using a physiological reaction such as electro-physical methods or otoacoustic emissions (Arlinger, 2007). Pure-tone average (PTA) is a common hearing test, relying on a patient's response to pure-tone stimuli. With PTA both air and bone conduction can be tested thus, enabling the determination of degree, type, and configuration of HL in an individual. Test frequencies begin at $1000 \mathrm{~Hz}$ and include at a minimum octave steps up to $8000 \mathrm{~Hz}$ and down to $125 \mathrm{~Hz}$. Often 750, 1500, 3000 , and $6000 \mathrm{~Hz}$ are also included. Figure 2 shows results from a PTA marked in an audiogram with test frequencies on the horizontal axis and hearing thresholds on the vertical.

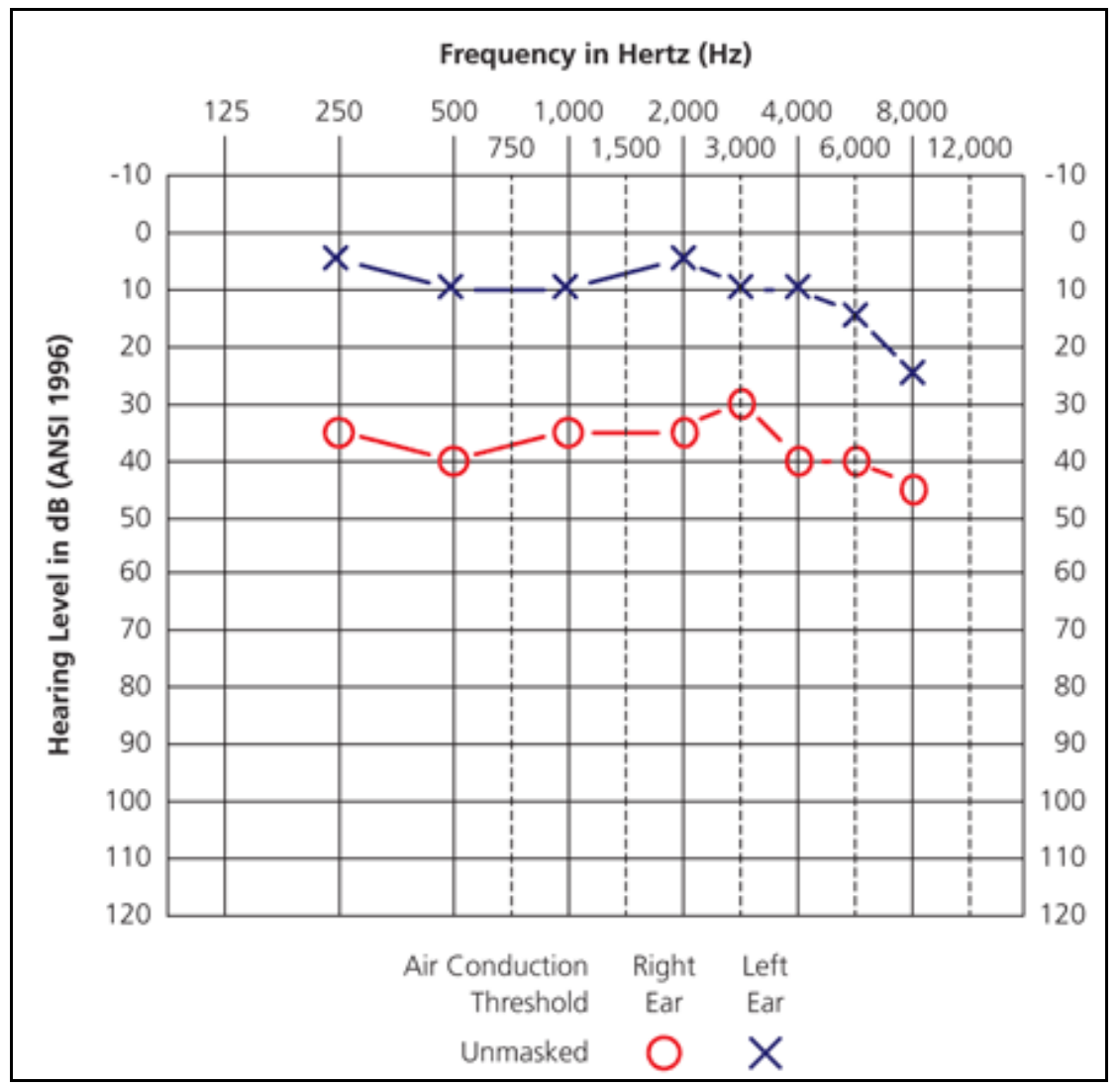

Figure 2: An audiogram presenting hearing thresholds from a PTA (air conduction). 


\section{Cognition}

Cognitive psychology is a necessary part for explaining human behavior. The cognitive approach is used to explain the mental processes essential for our ability to perceive and attend to, as well as memorize and communicate with, the world around us. These cognitive processes also are fundamental for our language perception, production and use, thinking, and problem solving (Eysenck \& Keane, 2010). The concept 'attention' is successively being replaced by executive functions (EFs), which are defined as a high-level process with the main obligation of adapting to new and complex situations (Diamond, 2013; Eysenck \& Keane, 2010). Working memory (WM) and long-term memory (LTM) are 2 separate memory systems, which according to Baddeley (2012) are linked together by an episodic buffer working as an interface between the 2 memory systems. In order to understand the possible cognitive consequences of HL relevant for traffic safety it is important to understand both cognitive consequences of HL and road user behavior.

The main focus in the present thesis is on car drivers with age- related HL. WM, LTM and EFs are involved since previous research has shown the effects of age (e.g., McDowd \& Shaw, 2000; Verhaeghen et al., 2003) and HL (e.g., Andersson \& Lyxell 1999; Lin et al., 2011, 2013; Rönnberg et al., 2011) on these systems. Cognitive factors such as perception and decision making is not actively examined even though effects of aging have been observed in previous studies (e.g., Johnson, 1989; Kennedy, Taylor, Reade, \& Yesavage, 2010). The reason for this is the limited knowledge in this area and there is a need for constraints to be able to focus on some specific issues.

\section{Working memory}

WM refers to a memory system with a limited capacity, and that serves to simultaneously store and process new information over a short period of time (Daneman \& Carpenter, 1980; Daneman \& Merikle, 1996; Miyake \& Shah, 1999; Baddeley, 2012). WM is necessary in daily life in that it helps us keep things in mind when approaching a task. For example, remembering what to write down once we have found the piece of paper and a pencil or remembering what we have read once we get to the end of the sentence. In the multicomponent 
model of WM (Baddeley, 2012; Repovs \& Baddeley, 2006) there are 4 components, each serving a specific purpose. A central executive serves as a modality independent control system, which directs and divides attention between tasks. It is involved whenever manipulation within WM is required (Repovs \& Baddeley, 2006). This means the central executive controls the function of the subordinate storage components, namely: the phonological loop (dealing with language-based verbal information); the visuospatial sketchpad (processing visuospatial information); and the episodic buffer (providing a link between new and old information) (Repovs \& Baddeley, 2006).

The phonological loop comprises 2 components: a passive phonological store, which holds memory traces, like speech, in acoustic or phonological form for a few seconds; and an articulatory rehearsal process linked to speech production, recoding information from other modalities (Repovs \& Baddeley, 2006). According to this words and letters presented auditorily are processed differently from those presented visually. Auditory sensations have direct access to the phonological store, regardless of whether the articulatory control process is used. In contrast visual presentation of words and letters only produces indirect access through sub-vocal articulation (Baddeley, 2012; Eysenck \& Keane, 2010).

The visuospatial sketchpad is dedicated to the storage and manipulation of visual and spatial information. The fourth component is the episodic buffer, which serves as an interface for binding information from different sensory sources, the other 2 subsidiary systems, and LTM. The episodic buffer also serves as an interface between perception and LTM, where the phonological and semantic representations in the lexicon are stored (Baddeley, 1983; Repovs \& Baddeley, 2006). WM capacity is related to performance in most other complex cognitive tasks such as reading comprehension and problem solving (Conway, Kane \& Engle, 2003). WM capacity is one reflection of individual differences in the ability to focus and maintain attention, specifically when other events are serving to capture one's attention (Kane \& Engle, 2002).

In sum, WM is the ability to temporarily hold information, manipulate and use this for a special cause over a short period of time. One example from a traffic situation is a road user (driver, pedestrian or cyclist) who is about to cross the street. They must keep track of the positions of the other road users and use this information to calculate when to cross.

\section{Long-term memory}

LTM is a memory system where information is stored for long periods of time and remains indefinitely. In this system, declarative memory includes episodic 
memory and semantic memory, while non-declarative memory is divided into repetition priming and procedural memory (Eysenck \& Keane, 2010). Episodic memory is the memory of personal events (e.g., times, places, associated emotions, and other contextual knowledge) that can be explicitly stated, which is used when driving to a specific known place. The semantic LTM includes general knowledge about the world (e.g., languages, game rules, names of capital cities, authors of books, traffic rules) that the individual shares with others. The perceptual representation system recognizes items and terms, permitting rapid identification of previously encountered stimulants (perceptual or conceptual). As the name implies, procedural memory stores information on how to perform certain procedures such as walking, riding a bike and maneuvering a car (Eysenck \& Keane, 2010).

\section{Executive functions}

EFs are a set of mental processes that help us stay focused on what we are supposed to focus on (Diamond, 2013). EFs is a relatively new concept in the sense that we can relate to it more theoretically today than previously. EFs are used to perform activities such as planning, organizing, making, and using strategies, paying attention to and remembering details, and managing time and space. EFs make it possible to play with ideas, take the time to think before acting, meet novel, unanticipated challenges, resist temptations, and stay focused (Diamond, 2013). Miyake et al. (2000) defined shifting, updating and inhibiting as 3 specifically important EFs, correlated but separable. Shifting was defined by Monsell (1996) as responsible for attentional or task shifting. Updating monitors and codes incoming information according to relevance for the current task. This manipulation, instead of just storing, was described as the most important function of the updating function by Morris and Jones (1990). Miyake defined inhibition as the possibility of deliberately stopping dominant, automatic or powerful reactions and necessary to minimize distraction effects (Miyake et al., 2000).

Researchers have argued that WM capacity reflects the efficiency of EFs, especially the ability to maintain a few task-relevant representations and neglecting irrelevant information (Engle, Tuholski, Laughlin, \& Conway, 1999). According to Diamond (2013), the main EFs are: inhibition, which is divided into response inhibition (self-control-resisting temptations and resisting acting impulsively) and interference control (selective attention and cognitive inhibition); WM; and cognitive flexibility (including creatively thinking outside the box, seeing anything from different perspectives, and quickly and flexibly adapting to changed circumstances). 
In sum, EFs are essential in helping us in our daily life. They help us stay focused on what we are doing by updating us with relevant information and neglecting unrelated information. EFs also help us shift between tasks and think before acting, which is essential for driving a car. For example, visualization of consequences, analysis of information, and judgment of time, distance and power are necessary to be able to drive a car safely.

\section{Assessment of cognitive ability}

Cognitive decline is, just like HL, a part of normal aging and also related to HL (Baltes \& Lindenberger, 1997; Rönnberg et al., 2011; Valentijn, van Boxtel, \& van Hooren, 2005). Therefore, it is important to control for differences in cognitive abilities when comparing driving performance between a group with HL and a group with NH. This can be accomplished by cognitive testing.

\section{WM capacity}

There are several tests designed to evaluate WM capacity. A commonly used measure is a dual-task paradigm combining a memory span measure with a concurring processing task. Daneman and Carpenter (1980) invented the first version of this kind of task, called the "reading span test". In their test participants read a number of sentences (usually between 2-6) and tried to remember the last word of each sentence. At the end of the list of sentences, they tried to repeat back the words in the correct order. Individual WM capacity, as measured by the reading span test (Andersson, Lyxell, Rönnberg, \& Spens, 2001; Daneman \& Carpenter, 1980; Rönnberg, 1990), has shown to account for $40 \%$ of the inter-individual variance of speech recognition in noise among participants with similar levels of HL (Lunner, 2003).

Impairments in visuospatial ability (measured by, for example, copying the wire cube, pentagons, drawing a clock face) are good markers of increased driving risk (Kipps \& Hodges, 2005). The clock drawing test (CDT) is a simple tool that is used to screen people for signs of neurological problems such as Alzheimer's and other dementias. CDT assesses primarily EFs by letting the participant draw a clock with hands pointing at a specific time.

TIPS (Text Information Processing System, Ausmeel, 1988), is a cognitive test platform developed according to established cognitive models of WM, phonological and lexical ability (see Baddeley, 2012; Abreu, Gathercole, \& Martin, 2011; Shah \& Miyake, 1996). The battery intends to measure WM capacity, phonological abilities and lexical abilities, and thus includes several tests for each of these cognitive aspects. A shorter computer-based version of TIPS was developed for use in clinics. Both this and TIPS have been used in a 
large number of studies (e.g., Hällgren, Larsby, Lyxell, \& Arlinger, 2001, Bergemalm, Hennerdal, Persson, Lyxell, \& Borg, 2009; Lidestam, Lyxell, \& Andersson, 1999; Hua, 2014). The reading span test aims to measure the WM capacity. Two tests include reaction time measure of phonological ability (deciding whether 2 letters are identical and deciding whether 2 words rhyme).

\section{Processing speed, divided attention, selective attention}

Skills measured by Useful Field of View (UFOV) are used during driving (Ball \& Owsley, 1993), and the test is intended to be indicative of accident risk in the older population (Ball, Owsley, Sloane, Roenker, \& Bruni, 1993; Owsley et al., 1998). In the first subtest, measuring processing speed, the participant is asked to identify which vehicle (car or truck) is displayed on the screen for a short time. In the second subtest, evaluating divided attention, the participant should, in addition to the first task, localize a car placed in the periphery on the screen. The third subtest, assessing selective attention, is identical to subtest 2 but with the rest of the screen filled with distracting triangles.

The trail-making test (TMT) assesses visual search, processing speed and mental flexibility (Reitan, 1986). Part A consists of targets marked with numbers, which are connected in numerical order, and part B are targets marked with both numbers and letters, which are connected in a combined numerical and alphabetical order such as 1-A-2-B-3-C and so on. On a computerized version of TMT developed by Summala et al. (2008), the target locations are fixed on the screen but the content, that is numbers or letters, are either the same (fixed) or randomly changed after each tap on a touch screen instead of the traditional pen and paper version.

\section{Hearing loss, cognition and aging}

Commonly, when talking about older people, older adults and elderly, this refers to individuals over the age of 65 (Gordon-Salant, 2005; Gorman, 1999; Roebuck, 1979). This also applies for this present thesis. Numerous studies have shown that there is a correlation between HL and cognitive decline in old age (Granick, Kleban, \& Weiss, 1976; Thomas, Hunt, Garry, Hood, Goodwin, \& Goodwin, 1983; Lindenberger \& Baltes, 1994; Baltes \& Lindenberger, 1997; Li \& Lindenberger, 2002; Lin, Ferrucci, Metter, An, Zonderman, \& Resnick, 2011; Rönnberg et al., 2011), which will be presented more specifically in a subsequent section.

Because age-related HL is the most common type (Roth, Hanebuth, \& Probst, 2001; WHO, 2001), it is important to understand other consequences of normal aging, which more or less affect or are affected by HL. For example, the 
deterioration of auditory functions such as like speech understanding is worsened by age-related changes in the cognitive system (Grady, 2012; Rönnlund, Nyberg, Bäckman, \& Nilsson, 2005). Older adults with NH have also shown more difficulties with speech recognition than younger individuals with NH (Frisina \& Frisina, 1997; Gordon-Salant, 2005), which can, for example, affect the possibility of using auditory-based driver assistance systems.

\section{Cognitive consequences of aging}

Aging is associated with the decline in the control processes involved in coordinating distinct tasks such as reaction times, WM tasks, tests of episodic memory, tests of spatial and reasoning abilities, mental rotation, and visual search performance (McDowd \& Shaw, 2000; Verhaeghen et al., 2003). However, on specific vocabulary tests, no effects of age have been shown, for example by Elliott et al. (2003) using the Wechsler Adult Intelligence Scale Vocabulary subtest (Jastak \& Jastak, 1964) and by Bowles and Salthouse (2009) using multiple-choice synonyms, multiple-choice antonyms and produce-thedefinition.

The effects of aging have also been demonstrated when switching between specific tasks (e.g., switching between responding to color or form and responding only to color, Mayr et al., 2001; Verhaeghen et al. 2005), and are also related to attention (Craik \& Salthouse, 2000; Phillips \& Lesperance, 2003). Slower cognitive processing is also associated with aging (Cerella, 1990; Salthouse, 1996) and it is estimated that processing takes 1.5-2 times longer in older than in younger adults (Cerella, 1990). This affects most age-related declines in performing complex cognitive tasks such as problem solving, reasoning and language comprehension (Salthouse, 1996; Verhaegen et al., 2003).

Aging is also associated with reductions in WM for both processing (van der Linden et al., 1994, 1999; Bopp \& Verhaeghen, 2005) and capacity (Bopp \& Verhaeghen, 2005; Salthouse \& Babcock, 1991). Specifically, the episodic memory of LTM is negatively affected by age while semantic memory remains relatively stable or may even increase, and on the non-declarative memory no conclusive aging effect has been shown (Brickman \& Stern, 2009).

Some of these age-related cognitive declines can be of major importance for safe mobility (e.g., reaction times, visual search performance, processing speed, problem solving), specifically for driving, which according to Groeger (2000) is one of the most complex and safety critical everyday tasks in modern society. 


\section{Cognitive consequences of $H L$}

Specific and general effects of HL on cognitive functions have been demonstrated (e.g., Andersson, 2002, Lin et al., 2011, Rönnberg et al., 2011). For example, a relationship between severe to profound HL and deficiency in certain aspects of phonological processing has been demonstrated and suggested to come from a gradual loss of specificity of phonological representations (Andersson, 2002; Andersson \& Lyxell 1999; Lyxell, Andersson, Borg, \& Ohlson 2003; Rönnberg et al., 2011; Classon, 2013). Andersson (2002) concluded that specific aspects of the phonological system deteriorate in the HL population as a function of auditory deprivation. In particular, the phonological representations are impaired and this impairment also affects the ability to rapidly perform phonological operations.

HL has been demonstrated as independently associated with accelerated cognitive decline (30-40\%) and incident cognitive impairment (24\%) among older adults during a six-year period. (Lin et al., 2011). These effects have been shown with the Modified Mini-Mental State test (Teng \& Chui, 1987), which is a verbal cognitive test, as well as with a non-verbal cognitive test (called Digit Symbol Substitution, Wechsler, 1981), in both cross-sectional and prospective studies (Valentijn et al., 2005; Peters, Potter, \& Scholer, 1988). Specifically, verbal tests have shown the relationship between HL and cognitive decline more extensively than non-verbal tests (Granick et al., 1976; Thomas et al., 1983).

The more general effects of $\mathrm{HL}$ on cognitive functions may affect traffic safety more and are in line with Baddeley (2012), who found that articulatory suppression leads to WM decline. Prospective studies have found accelerated cognitive decline and increased risk of dementia and Alzheimer's in individuals with HL (Lin et al., 2011, 2013). Cross-sectional studies have shown that HL is associated with lower performance in tests of EFs and free recall (Lin, 2011) and has a negative effect on episodic and semantic LTM (Rönnberg et al., 2011). With a decline in WM, EFs and LTM, it might, for example, be more difficult to stay focused on the driving task, keep track of the surrounding traffic or to remember traffic rules.

Another aspect worth considering is cognitive fatigue, due to higher effort in listening, leading to decreased cognitive capacity. This effect has been shown on both young and adult listeners with HL (Arlinger, 2003; Hicks \& Tharpe, 2002; Tun, McCoy, \& Wingfield, 2009). In addition, several studies have shown that hearing aids do not fully restore speech difficulties of individuals with HL (e.g., Dimitrijevic et al., 2004; Moradi, Lidestam, Hällgren, \& Rönnberg, 2014; Nakeva von Mentzer, 2014), which made perceiving speech stimuli cognitively demanding (Moradi et al., 2014; Rönnberg et al., 2013). 
This cognitively demanding processing of speech stimuli may increase fatigue in individuals with HL during conversations with their partners while they are driving. Cognitive fatigue could, among other things, lead to decreased attention and thus be relevant to traffic safety. Moreover, mobility might be affected if cognitive fatigue leads to decreased driving.

Furthermore, dual sensory decline (hearing and vision) is associated with cognitive decline and for a functional decline on everyday activities over a period of 4 years (Lin, Guttierrez, \& Stone et al., 2004). Thus, research questions with regard to age-related HL and traffic safety require the combined study of several factors associated with declines due to aging.

In sum, specific cognitive declines of HL have been demonstrated and include, for example, phonological deficiencies (processing and representation) as a consequence of less auditory stimulation (specificity of phonological representations). Traffic safety might be affected due to a decline in WM, EFs and LTM, which can lead to difficulties to stay focused on the driving task, keep track of the traffic around or to remember traffic rules. Also, cognitive fatigue could lead to decrease in attention and thus be of relevance for traffic safety.

\section{Cognition and traffic safety}

Groeger (2000) described driving a car as one of the most complex and safety critical daily tasks in modern society (Groeger, 2000). Driving is a cognitively motivated and controlled task. When demands are high, driving is carried out in a force-paced way, while when the demands are low, in a more self-paced way (Peters \& Nilsson, 2006). Thus, workload is an aspect of driving that should be considered, and in this thesis the term cognitive workload is used, when others might be using mental workload. De Waard (1996) defined driver workload as the individual reaction to driving task demand and further refers to Rouse et al., who defined experienced load, which is not only task-specific but also personspecific. (Rouse Edwards, \& Hammer, 1993).

More specifically, workload is the specification of the amount of information processing capacity that is used for task performance. Therefore, workload depends on the individual, and owing to the interaction between operator and task structure the same task demands do not result in an equal level of workload for all individuals (de Waard, 1996).

Directly related to driving task demand is task complexity. According to de Waard (1996), complexity increases with an increase in the number of stages of processing that are required to perform a task. Task demand and complexity are mainly external, but both depend on subjective goals set for task performance. Difficulty of a task is related to the processing effort that is required by the 
individual for task performance, and is dependent on context, state, capacity, and strategy or policy of allocation of resources (de Waard, 1996).

Driving effort is dynamic, as the cognitive demands can change back and forth from very low to extremely high, sometimes within fractions of a second (Michon, 1985; Peters \& Nilsson, 2006). Among the factors determining the driving task demand, of which the driver has immediate and direct control, driving speed is the most significant (Fuller, 2005). It has been demonstrated that when a threshold of a certain preferred driving speed is exceeded, experienced task difficulty, effort and feeling of risk is affected (Lewis-Evans, 2011).

In sum, driver workload is the individual reaction to driving task demand, which is directly related to task complexity. Task demand and complexity changes back and forth due to external circumstances and subjective goals, which makes the driving task and driver workload very dynamic. Feelings of risk arise when the task complexity goes above a certain threshold.

\section{Driver behavior models}

An advance within traffic behavioral research has been the increased understanding of the driving task from a cognitive perspective, and consequently the skills needed for carrying out this task successfully and safely. Since perceptual and psychomotor abilities are essential to model driving behavior, driving can be viewed as a cognitive task of control in a context perceived through the senses and manipulated with control actions based on unconscious (automated) or conscious decisions (Peters \& Nilsson, 2006).

Carsten (2007) distinguishes between 2 broad types of driver models. The first type is descriptive of parts or the whole of a driving task in terms of what the driver has to do and includes, for example, task models (Michon, 1985; McKnight \& Adams, 1970), adaptive control models (McRuer et al., 1977; Hollnagel et al., 2003), and production models (Michon, 1985). Michon (1985) described driving a car as a complex task with processes at a minimum of 3 hierarchical levels. At the top level, the strategic level, strategic decisions are made such as the choice of means of transport, setting of a route goal, and routechoice while driving. At the intermediate level, the maneuvering level, reactions to local situations, including reactions to the behavior of other traffic participants, take place. Basic vehicle-control processes, such as lateral-position control, occur at the lowest level, the control level. At this level automatic processes occur, while at higher levels higher controlled processing is required.

The second type is motivational models, aiming to describe how the driver manages task difficulty. In contrast to the descriptive models, sometimes being merely descriptive or analytical, motivational models attempt to explain which 
psychological factors affect driver behavior and why drivers make certain decisions (Michon, 1985).

According to Ranney (1994), errors associated with the variability of human behavior may be more important to roadway crash causation than systematic errors, which are attributable to the known limits of the human informationprocessing system. Furthermore, given the ever-increasing variety of driving situations, including changes in the driving task associated with different technologies, and the corresponding variety of skills and abilities required, Ranney (1994) claimed it unlikely that a comprehensive model of driver behavior will ever be feasible.

For the purpose of this thesis, we expect that differences related to HL are not as likely to occur in terms of what the driver has to do, but rather may occur in the management of task difficulty and when making certain decisions. Therefore, motivational driver behavior models will be presented and discussed in more detail from the HL perspective.

\section{Motivational models}

The most well-known motivational model is Wilde's (1982) Risk Homeostatis Model (RHM), introducing the notion of driver capability affecting risk (Carsten, 2007). Wilde proposed that there is a preferred target level of risk of being involved in an accident that drivers seek to maintain. Fuller and Santos (2002) proposed the Task Difficult Homeostasis (TDH) (see also Fuller, 2005, 2007; Fuller et al., 2008; Fuller, McHugh et al., 2008), stating that people have a set range of experienced task difficulty at which they prefer to operate. TDH was then re-conceptualized into Risk Allostasis Theory (RAT), where the acceptable range of task difficulty is accompanied by and essentially interchangeable with a range of preferred feeling of risk (Fuller, 2008; Fuller, 2011).

The Risk Monitor Model (RMM) (Vaa et al., 2000; Vaa, 2003, 2007, 2011) suggests that all individuals have a drive to maintain or obtain a target best feeling, which is variable in both its value and the type of feeling, however, including, for example: tension or anxiety, arousal, sensation, pleasure, relaxation, difficulty avoidance, compliance, and non-compliance (Vaa, 2007).

The Multiple Comfort Zone model (MCZ) by Summala (2005) is an evolution of the earlier zero-risk theory (Näätänen \& Summala, 1974). Being a motivational model it views a driver's excitatory motives, personality and driving goals as prevailing factors. These motives interact with the road system and push drivers toward changing their behavior to satisfy their driving goals, for example by increasing speed to arrive at a destination on time (Summala, 2005; Summala, 2007). 
What the presented motivational models all have in common is the level of risk, and it is suggested that the driver aims at maintaining this level. Whether drivers with $\mathrm{HL}$ are at higher risk than $\mathrm{NH}$ drivers or not is uncertain since there are studies suggesting connections between HL and higher risks of traffic accidents (Ivers, Mitchell, \& Cumming, 1999; Picard et al., 2008) and also research where no such relationship has been found (Green, McGwin, \& Owsley, 2013; McCloskey, Koepsell, Wolf, \& Buchner, 1994). However, if there is a difference in risk related to HL there should, according to the motivational models, also be a different level of risk in which the drivers with HL aim to maintain. This could be driving at a lower speed, for example.

Lewis-Evans (2012) experimentally tested 4 motivational models of driver behavior: TDH, RAT, RMM, and the MCZ (Summala, 2005; Summala, 2007). He concluded that the speed is not solely a conscious choice but handled, at least at some difficulty level, by automatic processes, and that the existence of these processes can be inferred when the cognitive capability of drivers is put to the test. Furthermore, results from the experiments supported the idea of a threshold to account for the perception of subjective variables such as task difficulty, effort, comfort, crash risk, and feeling of risk. For predicting difficulty of the task, the variables that the participants were most sensitive to changes in were speed and following distance. Lewis-Evans (2012) claims that these findings support models such as the MCZ (Summala, 2005; Summala, 2007) due to the reliance of this model on actual performance measures in driving such as time to line crossing or time to collision.

In line with Lewis-Evans' findings are the results from Lidestam, Lundqvist and Rönnberg (2010), who tested the external validity of theoretical driver behavior models by letting traffic inspectors rate the importance of theoretical concepts found in research literature on risk awareness. It was revealed that visual search was the most important concept, and that the assessment of risk awareness can be conceptualized as assessment of lower-order (maneuvering and position, cf. Michon's control level) and higher-order (attention, traffic behavior and speed, cf. Michon's manoeuver level) cognitive functions.

In sum, according to motivational driver behavior models, drivers aim to maintain a preferred level of risk. The results in Lewis-Evans (2012) with regard to speed and following distance suggest time-based safety margins as relevant measures of this individual level of risk, and visual search is proposed as a valid indicator of risk awareness (Lidestam et al., 2010). This is all in line with Gibson and Crooks' very first model of driver behavior: field of safe travel (Gibson \& Crooks, 1938). All of this is relevant for understanding the effect of HL on driving behavior and for the evaluation of driver support systems. Recurring in the models is the driving speed, and several studies have linked speed perception 
to the amount of noise in car cabins or to the driving sound (Evans, 1970; Ohta \& Komatsu, 1991). Thus, speed might be perceived differently by drivers with hearing loss, due to a reduced sensitivity to sounds. 


\section{Traffic safety}

One goal of traffic research should be to provide the safest possible mobility for all road users, regardless of their levels or types of abilities or disabilities. In all motivational models presented above, drivers aim to maintain a preferred level of risk, above a certain threshold. Whether drivers with HL are at higher risk than $\mathrm{NH}$ drivers is uncertain because previous findings are contradictory. For example, some studies found increased risk for drivers with HL (Ivers, Mitchell, \& Cumming, 1999; Picard et al., 2008), while others did not (Green, McGwin, \& Owsley, 2013; McCloskey, Koepsell, Wolf, \& Buchner, 1994).

According to Rumar (1988), there is always a risk in being mobile, and he divided risk into statistical (objective) risk and experienced (also called subjective or perceived) risk. For drivers with HL, research results are limited and rather contradictory on objective risk, and we found no results on subjective risk in our extensive literature surveys. Thus, it might be that drivers with HL can experience a subjective risk even if there is no objective risk. Research results so far do not identify clearly increased objective or subjective risks for drivers with HL, but this might be due to lack of knowledge. Therefore, there may be no increased risk at all for drivers with HL; there might be a small and unimportant risk; or there could be an important increased risk research has yet to reveal.

The level of knowledge on the relationship between HL and statistical traffic safety is relatively low and too inconsistent to draw any conclusions. Crash data have shown that drivers with HL are at higher risks of traffic accidents (Ivers, Mitchell, \& Cumming, 1999; Picard et al., 2008). However, there is also research on crash data and medical record data where such relationships have not been found (Green, 2013; McCloskey, Koepsell, Wolf, \& Buchner, 1994). On the effect of HL on subjective traffic safety the literature is even scarcer. Lundälv (2004) found that adult pedestrians and cyclists with moderate HL had no selfreported experiences of feeling insecure in the traffic environment; however, he also suggested that these individuals are at higher risk of being injured by a vehicle because they report that they find it difficult to identify the direction sounds come from. 
While traffic safety and mobility for drivers with HL is almost unexplored, the research literature regarding older drivers is relatively extensive. With agerelated HL being the most common type (Roth, Hanebuth, \& Probst, 2001; WHO, 2001), the effects of age are very relevant and will be discussed further in the following sections, along with the possible effects of HL.

\section{Mobility and quality of life}

Transportation is a part of everyday life and may be necessary for participation in activities and social life. Several studies suggest that travel habits will further increase for older adults in the future (Dillén, Schmidt, \& Jarlebring, 2005; Hausten et al., 2013; Hjorthol, Levin, \& Sirén, 2010) and this is explained by attitudinal effects (higher mobility needs, more active lifestyles), improved physical possibilities (fitness and health conditions), and cohort effects (being born at about the same time, exposed to the same events in society, and influenced by the same demographic trends and thus having similar experiences; Haustein, 2013).

In this thesis, mobility refers to the quality or state of being mobile - the ability to move freely. The ICF model includes mobility in activity and participation. Several studies have proven that limitation of activities increase with the degree of HL (Gopinath, Schneider, Hickson et al., 2012; Grue et al., 2009; Wallhagen et al., 2001; Schneider et al., 2010). HL has also been found to affect instrumental activities such as talking on the telephone or using public transportation more than daily activities such as getting dressed or eating (Gopinath, Schneider, McMahon, et al., 2012).

Car access is associated with better health and well-being among the elderly (Ellaway, Macintyre, Hiscock, \& Kearns, 2003; Macintyre, Hiscock, Kearns, \& Ellaway, 2001). By enabling older people with physical limitations to still live independently and to participate in normal daily activities, the car can act as a compensational tool for functional limitations (Sirén \& Hakamies-Blomqvist, 2004, 2009). According to Köpke, Deubel, Engeln and Schlag (1999), car availability and car use are related to positive self-perception in older people, and research suggests driving cessation may be a risk factor for a depressive development (Fonda, Wallace, \& Herzog 2001; Marottoli et al., 1997). With agerelated HL being the most common type of HL (Pearson et al., 1995; Schneider, Pichora-Fuller, \& Daneman, 2010) and with increasing travel habits among older adults (and the gap between actual mobility and desirable mobility), it is important to understand the effect of HL on mobility.

Self-regulation of driving usually refers to the voluntary reduction or avoidance of certain (typically challenging or demanding) driving situations 
(Haustein, 2013). This could also be a way of maintaining the level of risk by not exposing oneself to specific traffic situations. Factors found to be associated with self-regulation of driving are functional decline, and increasing cognitive and visual restrictions (Ball et al., 1998; Charlton, Oxley, Fildes, Oxley, \& Newstead, 2003; Holland \& Rabbit, 1992), and one's perceived driving skills (Gabaude, Marquié, \& Obriot-Claudel, 2010; Rimmö \& Hakamies-Blomqvist, 2002).

The most common medical conditions affecting driving cessation include sensory problems, cognitive impairment, stroke, cardiovascular, and other heart conditions, diabetes, and physical mobility and activity problems (Brayne et al., 2000; Dellinger, Kresnow, White, \& Sehgal 2004; Forrest, Bunker, Songer, Cohen, \& Cauley, 1997; Hakamies-Blomqvist \& Wahlström, 1998). Edwards et al. (2009) indicated that driving cessation is associated with declines in physical and social functioning, as well as in general health (Edwards, Lunsman, Perkins, Rebok, \& Roth, 2009).

In sum, various age-related declines are associated with self-regulation and driving cessation. Because car access is associated with better health among the elderly, it is important to assist driving for older adults when possible. One way of achieving this is to ensure that driver assistance systems are also accessible for drivers with HL.

\section{Effects of aging on driving behavior}

Factors associated with old age and that have a negative impact on the ability to drive include impaired perceptual abilities, memory decline, reduction in the ability to sustain and switch attention, and mobility constraints (Groeger, 2000). However, aging is usually a gradual process and while some skills deteriorate with increasing age, others (more strategic) are used more with increasing age (Haustein, 2013).

As car drivers, older persons perceive certain driving situations and conditions as demanding and potentially dangerous. These include driving in specific weather conditions (e.g., fog, rain or a storm), when feeling physically unwell or excited, in high traffic density, on specific road types (e.g., motorways or highways), on roads with certain characteristics (e.g., signals, traffic lights, curves, roundabouts), and in response to others' driving behaviors (e.g., tailgating) (Jansen et al., 2001; Sullivan, Smith, Horswill, \& Lurie-Beck, 2011).

Compensatory strategies addresses the regulation of loss as a function of aging or disability (Riediger, Li, \& Lindenberger, 2006; Lindenberger, Lövdén, Michael Schellenbach, Li, \& Krüger, 2008). It involves efforts (consciously or unconsciously) to maintain a given level of functioning despite decline in, or loss 
of, previously available resources (Riediger, Li, \& Lindenberger, 2006; Lindenberger, Lövdén, Michael Schellenbach, Li, \& Krüger, 2008; Donorfio, Mohyde, Coughlin, \& D’Ambrosio, 2008; Haustein et al., 2013; Monterde-iBort, 2004). Compensation, in contrast to optimization, aims at counteracting or avoiding losses rather than achieving higher levels of functioning (Riediger, Li, \& Lindenberger, 2006). When driving, compensatory strategies could be a way to maintain the level of risk as described in the driver behavior models.

Older drivers often show a more defensive driving style with lower average speeds (Chipman, MacGregor, Smiley, \& Lee-Gosselin, 1992; Haustein et al., 2013) and keep a larger following distance (Rajalin, Hassel, \& Summala, 1997). Age-related changes in driving patterns can be seen as a strategy to compensate for age-related decline and thus prolong the period of independent safe mobility (Donorfio et al., 2008).

In psychology, coping refers to the use of conscious effort to solve personal and interpersonal problems, seeking to master, minimize or tolerate stress or conflict (e.g., Ben-Zur, 2009; Carver \& Connor-Smith, 2010). One way of coping can be to simply avoid situations that cause stress or discomfort. Older drivers have been found to choose not to drive in certain conditions or environments and avoid risk-taking (Haustein et al., 2013). Driving conditions avoided by older drivers include rush hours, darkness, poor weather or road surface conditions, driving in unfamiliar areas (D'Ambrosio et al., 2008; Gwyther \& Holland, 2012; Hakamies-Blomqvist, 1994; Rothe, 1990). Moreover, older drivers are less likely than middle-aged drivers to be engaged in distracting activities such as adjusting in-vehicle equipment or using a mobile phone (Fofanova \& Vollrath, 2012; McEvoy, Stevenson, \& Woodward, 2006). Avoidance of distracting activities while driving is one coping strategy.

To summarize, the ability to drive is affected by the deficits that come with age and lead to changes in driving behaviors. The behavioral patterns of older drivers are more cautious and include both compensatory strategies (e.g., lower speed, longer distance) and coping strategies (e.g., avoidance of certain situations or distracting activities).

\section{Assessment of driver behavior}

According to de Waard (1996), good reflectors of primary-task performance at the control level (c.f. Michon, 1985) are measures of lateral position (LP) and steering wheel (SW) movements and at the maneuvering level (c.f. Michon, 1985) include the time-to-line-crossing (TLC; Godthelp, 1984). Standard Deviation Lateral Position (SDLP) has been shown to be a sensitive performance measure (e.g., Hicks \& Wierwille, 1979, O’Hanlon et al., 1982, O’Hanlon, 
1984). De Waard (1996) showed that increased road complexity could lead to an increase in the SD of the SW movements, while the addition of a secondary task reduced the SD of the SW movements. Manipulation of both driving speed (e.g., Fuller, 2008; Summala, 2007; Levis-Evans, 2012) and degree of engagement in secondary tasks (Fuller, 2005) may be most important in maintaining the preferred level of risk.

Visual-search strategy has been shown to be indicative of informational needs (Hughes \& Cole, 1988). According to de Waard (1996), eye-tracking measures are related to primary-task performance; however, they can also be used as a secondary-task performance measure in the case of embedded tasks. This is how eye tracking was used in the experimental studies in the present thesis. In the simulator study, driving was the primary task and an additional device was used for the secondary task. In the field study, drivers had to look at the navigation display to know which way to go. Relationships between frequency of fixation and instrument importance, as well as between length of fixations and difficulty in obtaining information from instruments, have been shown by Wilson and Eggemeier (1991). O'Donnell and Eggemeier (1986) reported that an increase in workload was accompanied by an increased fixation time.

\section{Advanced driver assistance systems}

One approach to accident prevention and injury reduction is the introduction of in-vehicle-based preventive safety functions, also known as Advanced Driver Assistance Systems (ADAS) (e.g., lane-keeping support, adaptive cruise controllers, collision warning systems). In contrast to protective, or passive, invehicle safety functions (e.g., seat belt, airbag), whose purpose is to mitigate crash consequences, the general goal of ADAS is to prevent crashes from occurring at all. This is meant to be achieved either by alerting the driver to potential hazards (warning) or by taking over the driving task to some extent (intervention), using, for example, autonomous braking in emergency situations (Ljung Aust, 2012). Carsten and Nilsson (2001) made the distinction between information systems, that interact with the driver, and other intervening systems, that interact directly with the vehicle. Navigation systems are typical of the former category and adaptive cruise control of the latter.

An ADAS typically consists of one or more environment sensors mounted on the vehicle, for example radars or cameras. Software that uses sensor input determines what actions the ADAS should take and the particular driver or vehicle interface is used to alert the driver or control the vehicle. Examples of safety technologies, which fall under the ADAS umbrella, are Forward Collision 
Warning (FCW), Adaptive Cruise Control, Lane Departure Warning, and Drowsiness Warning (Ljung Aust, 2012).

A key issue for ADAS systems is to verify that they actually improve traffic safety. While the safety potential of ADAS can be affected by many factors, Carsten and Nilsson (2001) proposed that all safety implications can be classified as belonging to either of three general aspects: the function safety aspect (technical reliability of the system); the Human Machine Interaction (HMI) aspect (operating, and communicating with, the system); and the traffic safety aspect (system influence on driving behavior, including changes in interactions with other road users).

Relevant for both the HMI aspect and the traffic safety aspect is the multiple resource theory (MRT) presented by Wickens and Hollands (1999). This theory describes information processing with stages (perception, WM and cognition, responding), modalities (visual, auditory) and codes (verbal, spatial). An important implication of the difference between processing codes is the ability to judge which control to use for response. Manual control may reduce performance if there are heavy demands on spatial working memory, for instance while driving, whereas voice control may disturb the performance of tasks with heavy verbal demands (Wickens \& Hollands, 1999).

The HMI aspect is central to the effect of HL on the use of driver assistance systems, since communication with the system must be set such that $\mathrm{NH}$ is not crucial, meaning that output cannot be only auditory. Several studies have shown that tactile support is an intuitive and effective way of presenting direction information and alerting drivers to potential collisions (van Erp \& van Veen, 2004; Ho, Tan, \& Spence, 2005; Ho, Reed, \& Spence, 2006). From the traffic safety aspect, this may release other heavily loaded sensory channels and therefore potentially provide a major safety enhancement.

Another issue is whether there are effects of HL on driving behavior. Concerning the fact that most HL is age-related, Li and Perkins (2007) showed that seniors view technology in the same way as the general public, and that education has a larger influence on the willingness to learn about new technology than age does. For training, simulators can be used to provide handson experience of new driver support systems and may therefore be valuable supportive tools for the elderly driver (Peters \& Nielsen, 2007).

In sum, ADAS aim to increase traffic safety by preventing crashes. To make the systems accessible for drivers with HL, alternatives to auditory signals are necessary. Tactile signals have been shown to be effective and intuitive in warning and providing directional information. 


\section{General aim and research questions}

The general aim of this thesis is to investigate traffic safety and mobility for individuals with HL from a perspective of cognitive psychology by using subjective and objective performance indicators. With the limited previous research and knowledge on this specific topic, the approach has been necessary exploratory. Three studies were conducted: a questionnaire survey and two experimental studies, whereof one driving simulator study and one field study. The overall aim of the questionnaire study was to evaluate whether there were any differences related to HL with regard to the choice of transportation or on the view of hearing in transport situations. With the limited previous knowledge in the field, there were no expected differences between the groups. The studies following the questionnaire study had more specific research questions and expectations. Henceforth, the population included in the studies was older adults, in order to create homogenous groups and also because the majority of HL is age-related.

Based on the results from the survey, the driving simulator study was conducted to examine if HL had an effect on driving behavior or on increased workload. Gaze data was analyzed to compare visual behavior and in addition, the efficiency of a tactile signal to alert the driver was evaluated. A more cautious driving behavior was expected among the drivers with HL, because of compensatory strategies such as longer distance to other vehicles, lower driving speed and a more active visual search behavior. Coping strategies such as paying less attention to the secondary task were also expected.

A field study was conducted to replicate and validate the effects from the simulator study in real traffic. In the field study, the aim was to also evaluate a driver assistance system (navigation system) with a supportive tactile signal. Compensatory strategies such as slower driving speed and more glances in the mirrors were expected for the drivers with HL. The tactile support was expected to lead to more focus on the road, better driving performance and higher satisfaction with the system. 


\section{Methods}

\section{Ethical considerations}

In the studies presented in this thesis, the aim was to create as homogenous groups as possible with regard to age-related HL, and to control for vision loss and cognitive decline. Ethical considerations mainly concerned integrity issues (no data could be tracked back to any individual). Potential ethical problems identified in the studies include missing or lacking information with regard to the aim of the studies, the optional participation (participants could resign at any time without having to give any motive), the noncompulsory sharing of personal audiograms, and the receipt and treatment of the audiograms. All of the studies presented in this thesis were conducted during 2011-12 in Linköping and received ethical approval from the Research Ethics committee (Etikprövningsnämnden, EPN 2011/125-31; 2012/345-31) in Linköping.

\section{Methodological challenges}

There were three different assessments to evaluate the effect of HL on traffic safety and mobility: the assessment of HL; the assessment of cognition, and the assessment of traffic safety each challenging and each with several possible methods. The results from each assessment were then to be put in relation to the other 2, which was even more challenging. Some of these challenges are presented in this section.

\section{HL population and recruitment of participants}

Individuals with HL constitute a heterogeneous population due to a large variation in age, level of HL, and onset and cause of HL. Additionally, HL may be either unilateral or bilateral. This heterogeneity, in combination with the low level of knowledge in the area of HL and traffic safety, makes designs with sharp hypothesis-testing difficult to conduct. However, the population is large and thus, for the experimental studies and from a heterogeneous population included in the questionnaire study, we recruited as homogenous a group as possible. This 
was sensible and realistic, and provided a perspective based on the reality of those living with HL.

Geographical differences and variations in driving experience had also to be considered. Traffic situations may be very different in large cities and small towns, and individual driving experience may affect how people cope with any particular situation. However, in the studies included in this thesis, all participants were recruited from the same region and at least mileage per year and years with a driver's license was controlled for.

As well as HL, loss of vision is also a part of normal aging (e.g., Risacher et al., 2013; Heyl \& Wahl, 2012). Wearing glasses can cause problems with eye tracking (Eachus, Cassidy, Norgate, Marrow, \& Greene, 2008; O'Brien \& Sharon, 2009), and this consideration restricted our potential participants. Furthermore, there will always be uncertainty of the representativeness of participants in any study. Not all individuals are willing to take part in research studies, and there is a risk that whatever characterizes those willing to participate from those not willing will lead to systematic sampling errors.

Response rate and completeness of questionnaires are difficult to control when participation is voluntary. There are arguments for and against using Internet (electronic) or paper and pencil versions. One advantage of electronic versions, besides the efficiency of receiving all answers in a database, is the opportunity to control that all questions have been answered before submission. However, paper versions have been found to have a higher response rate than electronic versions (73.2\% compared to $17.9 \%$, respectively) (Kongsved, Basnov, Holm-Christensen, \& Hjollund, 2007).

\section{Driving simulator versus real driving}

The advantages of performing simulator studies, including the opportunity to offer a safe convenient alternative to measuring driving performance on the road and the ability to keep driving conditions and environmental conditions constant, also come with limitations (Mullen, Charlton, Devlin, \& Bédard, 2001; Nilsson, 1993). For example, motion, velocity and acceleration ranges are limited. It is impossible to fully represent a real traffic environment, and there is also the chance of simulator sickness, a type of motion sickness specifically experienced in simulators (Nilsson, 1993). Moreover, the simulated world does not contain the same level of detail and roughness as the real world. Since there is a limited amount of details in the simulated world, there is also less to focus on. It is not known how much this limitation affects visual behavior. Simulator performance shows medium to strong correlations with many on-road driving performance measures, and with other cognitive and physiological measures. However, simulators must be validated for each new setting (Mullen et al., 2001). 


\section{Challenges with cognitive assessments}

One of the greatest concerns when creating a test for cognitive assessment is whether or not it actually measures what we think it is measuring. A test has construct validity if it demonstrates an association between the test scores and the prediction of a theoretical characteristic. Hughes, Sapp, and Kohler (2006) presented the challenges of conducting accurate cognitive assessments of students with HL. The authors pointed out that poor performance on an assessment may not necessarily indicate lower ability, but may be the result of a misunderstanding of the type or language of the assessment. Thus, they suggested using a variety of measures to assess participants, especially individuals with HL.

\section{Procedures and validity}

Procedures and validity are first discussed for the questionnaire study and then for both of the experimental studies since several measures are included in the simulator study and the field study.

\section{Questionnaire study}

Along with questions about hearing and transport habits, aspects found in the literature to be avoided by older drivers were included in the questionnaire (long distances, rush hours, darkness, poor weather, road surface conditions, and driving in unfamiliar areas) (D'Ambrosio, 2008; Gwyther, 2012; HakamiesBlomqvist, 1994; Rothe, 1990). In the questions about traffic incidents and accidents definitions from a report from the Swedish Road Administration (STRADA, 2007) were used.

Questionnaire responses were mainly scored using a 5-point scale. The odd number was chosen to allow neutral answers, and 5 points was chosen instead of a larger number because the data were not expected to be skewed in either direction (Johnston, 2008). The alternatives of "do not know" or "not relevant" was also included to avoid forcing participants to tick wrong alternatives. A few open questions were also included to allow respondents to answer in their own words, and likewise after each closed question there was room for comments.

\section{Experimental studies}

According to de Waard (1996), self-report scales and performance measures are the most appropriate for workload assessment, and a useful experimental design in traffic research is to compare task performance in an experimental (e.g., mental load) condition with performance under baseline conditions. Evaluation 
of workload due to complexity should, according to de Waard et al., either involve an increase in road complexity or an increase in task complexity, for example with the addition of a secondary task. This approach was used in both experimental studies. In the simulator study, load conditions with and without a secondary task were compared with baseline conditions with and without the secondary task. In the field study, road complexity varied between city and ring road, while task complexity either by varied including a tactile support in the navigation system or leaving that out. Self-report scales during (only in the simulator study) and after the drive were used, as well as performance measures.

Critical incidents, law violations, and LP errors are measures of driving performance and have been used as such in task-performance assessments (e.g., Pohlmann \& Traenkle, 1994). In particular, complex behavior, such as the occurrence of critical incidents or behavior in a complex driving environment, can be easier, or more accurately, detected and judged by an observer than captured in a single performance measure (de Waard, 1996).

\section{Pretests}

In both experimental studies, hearing tests were performed on all drivers with $\mathrm{NH}$ and for participants with HL audiograms were provided from the audiology clinic. The inclusion criterion for the $\mathrm{NH}$ group was a hearing threshold of maximum $20 \mathrm{~dB}$ at each frequency $(500,1000,2000$, and $4000 \mathrm{~Hz})$, measured with a pure tone audiometer. Inclusion criterion for the HL group was a moderate HL (41-60 dB) according to WHO categories (Arlinger, 2007), measured with a pure-tone average of 4 mean values, PTA4 (means of 500, 1000, 2000, and $4000 \mathrm{~Hz}$ ).

In the field study (Paper IV), more pretests were included to control for differences between the experimental groups. Apart from HL, normal consequences of aging also include declining visual abilities, such as visual acuity and contrast sensitivity (e.g., Risacher et al., 2013; Heyl \& Wahl, 2012) and cognition (e.g., McDowd \& Shaw, 2000; Verhaeghen et al., 2003; Mayr et al., 2001; Verhaeghen et al., 2005, Craik \& Salthouse, 2000; Phillips \& Lesperance, 2003). Relationships between sensory and cognitive losses in older adults have also been presented (Clay et al., 2009; Heyl \& Wahl, 2012; Holland, 2009; Vreeken et al., 2013). Therefore, in the field study, vision tests and cognitive tests were included to control for differences between the groups.

Clinical vision measures included binocular distance visual acuity using a logMAR chart (Ferris, Kassoff, Bresnick, \& Bailey, 1982) and binocular contrast sensitivity ( $\log \mathrm{CS}$ ) using the Pelli-Robson chart (Pelli, Robson, \& Wilkins, 1988). Cognitive tests included: verbal ability (The F-test, Psykologiförlaget, Stockholm); a cognitive test battery, including physical 
matching, physical lexical matching, rhyme and reading span (Hällgren, Larsby, Lyxell, \& Arlinger, 2001); a computerized dynamic TMT, shown to be related to driving performance (Lehtonen, Dahlström, Hiltunen, \& Summala, 2012), and the Useful Field of View test (UFOV), measuring skills thought to be used during driving (Ball \& Owsley, 1993).

\section{Secondary task}

In the simulator study, to create 2 levels of cognitive workload in the secondary task the phonological similarity effect was used (Conrad \& Hull, 1964; Baddeley, 1968; Hitch \& Halliday, 1983), and the sequences consisted of randomized letters that were either phonologically alike (e.g., BDPT) or not phonological alike (e.g., RKNJ). Each letter was displayed for 0.7 seconds, which is an adaptation of Sternberg's scanning paradigm (Sternberg, 1966). The display time had to be long enough for recognition of the letters, but short enough for the participants to keep their eyes on the display.

\section{Performance indicators}

Performance indicators in the simulator study were mean LP, SDLP, minimum TLC (TLCmin; Brookhuis, Waard, \& Fairclough, 2003), mean driving speed, SD driving speed, and secondary task performance. For subjective ratings during the simulator test drive, the following question was presented on the screen after each event: How critical did you experience the situation to be? The participants answered on a scale from $1=$ not critical at all to $7=$ extremely critical. This is an adaptation (specifically the dimension of the degree of complication) from the Situation Awareness Rating Technique (SART) 10 Dimension-scale, with each dimension ranging from 1-7 (Endsley \& Garland, 2000).

In the field study, mean driving speed and SD driving speed were included along with eye tracking (specifically frequency and length of fixations) and driving performance assessment according to an on-road protocol (Selander, Lee, Johansson, \& Falkmer, 2011).

\section{Participants and data collection}

For the questionnaire survey, participants were recruited from the local branch of the Swedish hard of hearing association. A control group with normal hearing $(\mathrm{NH})$, matched with age, gender and geographical location, was then selected from a commercial database. The survey was also used to recruit participants for the other studies by including a question about their interest in taking part in further research in the field of HL and traffic safety. The VTI participant database was used to recruit participants with $\mathrm{NH}$. Information about 
participants' demographic details is listed in Table 1 together with the data collection method used for each study.

Table 1: Participants' demographic details and data collection method in the studies.

\begin{tabular}{|c|c|c|c|c|}
\hline Study & Participants & $\begin{array}{c}\text { Gender } \\
\text { (Male/Female) }\end{array}$ & $\begin{array}{l}\text { Age Mean (SD) } \\
\text { Male/Female }\end{array}$ & $\begin{array}{l}\text { Data collection } \\
\text { method }\end{array}$ \\
\hline $\mathrm{I}$ & $\begin{array}{l}93 \text { self-reported NH } \\
48 \text { mild HL } \\
105 \text { moderate HL } \\
47 \text { severe HL } \\
18 \text { profound HL }\end{array}$ & $\begin{array}{l}50 / 43 \\
17 / 31 \\
44 / 61 \\
28 / 19 \\
7 / 11\end{array}$ & $\begin{array}{l}71.5(13.2) / 63.4(14.5) \\
69.0(11.1) / 68.7(12.4) \\
74.8(7.7) / 61.1(15.9) \\
55.5(15.1) / 75.1(14.7) \\
57.3(12.6) / 65.8(9.7)\end{array}$ & $\begin{array}{l}\text { Questionnaire } \\
\text { survey }\end{array}$ \\
\hline II & $\begin{array}{l}24 \mathrm{NH} \\
24 \text { moderate HL }\end{array}$ & $\begin{array}{l}12 / 12 \\
13 / 11\end{array}$ & $\begin{array}{l}60.1(7.1) / 59.6(5.0) \\
62.0(7.9) / 61.0(9.8)\end{array}$ & $\begin{array}{l}\text { Driving } \\
\text { simulator study } \\
\text { with driving } \\
\text { performance, } \\
\text { eye tracking, } \\
\text { and survey }\end{array}$ \\
\hline III & $\begin{array}{l}16 \mathrm{NH} \\
16 \text { moderate HL }\end{array}$ & $\begin{array}{l}5 / 10 \\
7 / 8\end{array}$ & $\begin{array}{l}51.2(8.3) / 52.8(11.0) \\
60.2(12.4) / 53.0(13.3)\end{array}$ & $\begin{array}{l}\text { Field study with } \\
\text { eye tracking, } \\
\text { questionnaire } \\
\text { and driving } \\
\text { assessment }\end{array}$ \\
\hline
\end{tabular}

\section{Design and statistical analyses}

\section{Questionnaire survey}

Logistic regression (binary for dichotomous questions answered by "yes" or "no" and ordinal for questions with more than 2 ordered alternatives) was used to analyse the results of the questionnaire study because it was explorative and had no inbuilt expectations to examine. This is a type of regression analysis with binary or ordinal response variables. The probabilities describing the possible outcomes of a single trial are modelled as a function of the explanatory (predictor) variables, using a logistic function (Bishop, 2006).

All predictor variables were entered simultaneously, since there was no presumption of which one would explain more. The results from the logistic regression are presented using odds ratio $(O R)$, which quantifies how strongly the presence or absence of property $\mathrm{A}$ in the response variable is associated with the values on the predictor variables (McHugh, 2009; Mosteller, 1968). That is, this gives a measure of the influence of the predicting variables (e.g., degree of $\mathrm{HL}$, gender, age) on the dependent variable (e.g., having a driver's license). $O R$ $=1$ means no influence, $O R>1$ means an increasing probability, and $O R<1$ means a decreasing probability. 


\section{Driving simulator study}

The driving simulator study had a $2 \times 2 \times 2$ factor design with the fixed factors hearing status (NH vs. HL), gender (men vs. women), and difficulty level (lower vs. higher). Participant (participants 1-48) within hearing status and gender was included as a random factor. On driving behavior measures (e.g., speed) and secondary task, analysis with planned comparisons within and between the Hearing status levels was carried out using a mixed model. For the post-trip questionnaire, with questions on subjects including subjective driving performance on ordinal scales, logistic regression and $O R$ were used.

Analysis of gaze data was conducted in 2 steps. The strategy for analyzing the distribution of glances was to start with a model as comprehensive as possible, with several variables, interactions, and multidimensional responses. A multivariate analysis of variance (MANOVA) was performed to examine whether condition (with or without secondary task), hearing status, gender or any two-factor interactions of these had an effect on the distribution of glances, where the distribution is governed by a vector representing the 7 target gaze zones. In this model, hearing, gender and condition were included as fixed variables, and a participant nested within hearing and gender was included as a random variable. The significant interaction effect of condition and hearing led to the analysis of each condition and each hearing status. ANOVA (analysis of variance) were performed to test hypotheses examining one zone at a time.

\section{Field study}

In the field study a $2 \times 2 \times 2$ factorial design with the between-groups factor hearing status (NH vs. HL), and the two within-groups factors system information (visual vs. visual tactile), and complexity (lower vs. higher) were used. Generalized estimating equations (GEEs) were used to model correlated data from this repeated measures design. GEEs are used to estimate the parameters of a generalized linear model with a possible unknown correlation between outcomes, and have the advantage of overcoming the classical assumptions of statistics, for example independence and normality, which are too restrictive for many problems (Liang \& Zeger, 1986; James \& Joseph, 2003).

GEEs were used on the following linear or continuous outcome measures: speed, on-road performance, gaze behavior patterns, and usability questions. Predictor variables were system information (within subjects), hearing category, and age (between subjects). Outputs were Wald statistics $\left(\chi^{2}\right)$, showing the significance, and an unstandardized regression coefficient $(B)$, presenting the relationship between the groups. For background questions in the questionnaire, cognitive tests, and vision tests one-way ANOVAs were performed. 


\section{Summary of studies and papers}

In experimental psychology there are often several parts of a study presented in one paper. In this thesis, the studies are fewer and larger and have generated one or 2 papers each, which is more common in traffic safety research.

An overview of studies, papers, and findings is presented in Figure 2. Three studies were conducted and generated four scientific papers, which are included in this thesis. Since the initial level of knowledge was low and somewhat contradictory, a questionnaire study was the first step on the path to evaluate differences in traffic safety and mobility related to HL. The results from the first study are presented in the first scientific paper and also included in the background to the second study conducted in the driving simulator. The results from this study generated the second and third scientific papers and were (together with the results from the questionnaire study) included in the background to the third study conducted in real traffic. This study generated the fourth scientific paper. Summaries of each study are presented in the following sections. 
Study 1: Questionnaire survey

Paper I: The Effect of Hearing Loss on Traffic Safety and Mobility

Background

Limited research in this field.

Contradictory findings about the effect of HLon traffic safety and mobility.

Driver support systems offen auditory based.
Research questions

Does HLaffect

- choice of transportation?

- view of HLregarding transport situations?

- traffic safety?

-need and design of driver support systems?
Conclusions

There were fewer license holders with

HL. HL had no effect on mileage, incidents, accidents, or interest in driver support systems. Compensatory strategies might be applied by drivers with HL .

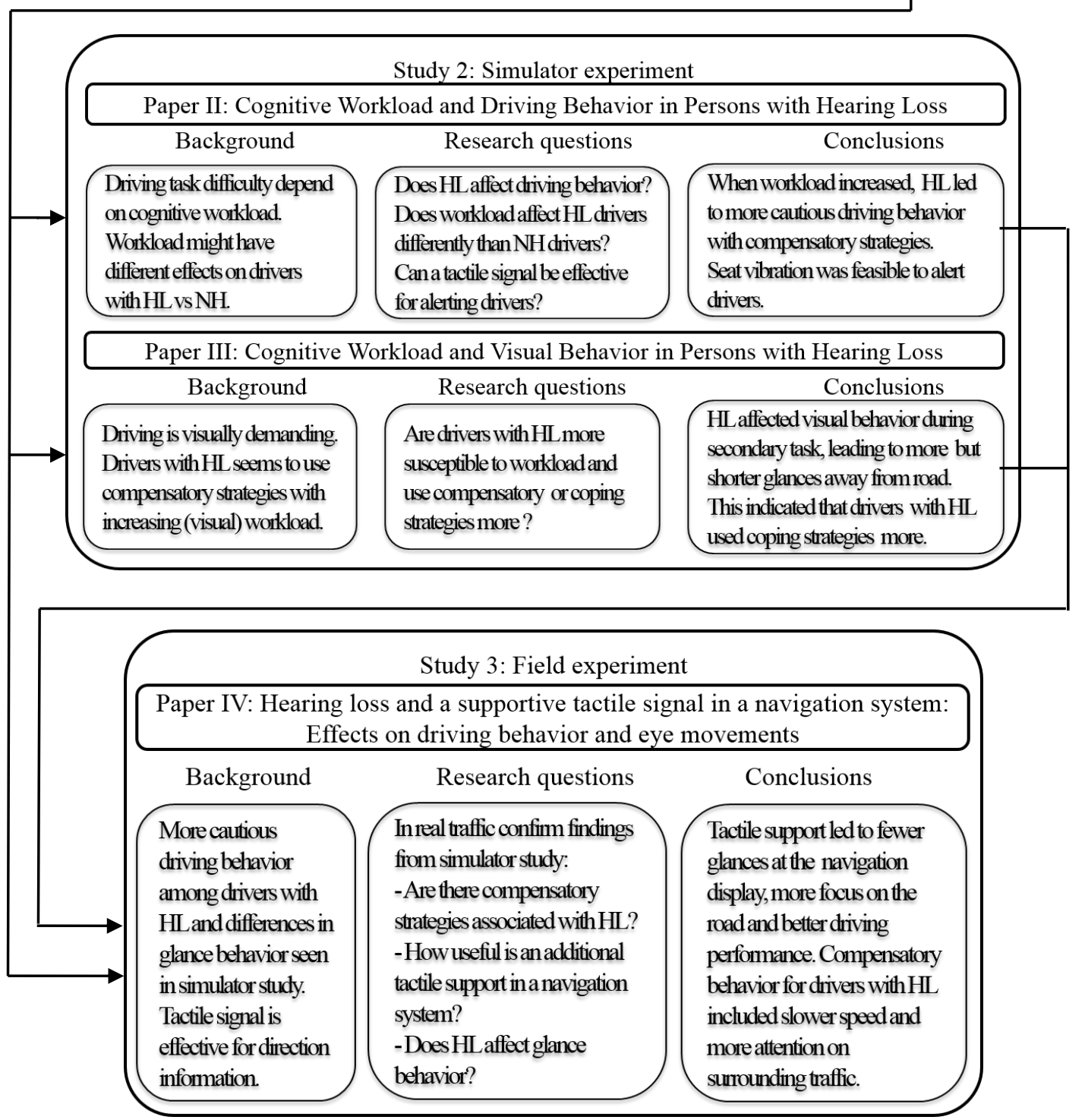

Figure 3: Overview of studies, papers and findings. 


\section{Study 1: A questionnaire survey}

\section{Paper I: The influence of hearing loss on transport safety and mobility}

\section{Purpose}

The purpose of study 1 was to examine how road users with different degrees of HL, compared to road users with $\mathrm{NH}$, experience traffic safety and mobility. Specifically, three general research questions were investigated: how HL affects the choice of transportation type (e.g., driving your own car vs. public transport); personal view of HL in relation to transport situations, and the need for and design of driver support systems (e.g., collision warning, parking aid, navigation systems, lane keeping systems) for drivers with HL.

\section{Method}

A questionnaire survey was conducted with participants recruited from the local branch of the Swedish Association for Hard of Hearing People (HRF). A NH control group, random and matched by age, gender and geographical location, was selected from a commercial database. From audiogram data, participants were sorted into groups according to their degree of HL. A web-based questionnaire was constructed to capture the 3 research questions mentioned above. With assistance from HRF, letters were sent out to members of their local branches with an invitation to take part in the study. There was also the possibility of receiving a paper version of the questionnaire. The response rate was $35 \%(n=194)$ in the group with HL and $42 \%(n=125)$ in the group with $\mathrm{NH}$. The individuals with hearing loss were grouped into four groups according to the degree of their hearing loss (mild, moderate, severe, and profound). After receiving permission from the participants, audiograms were provided by the local audiology clinic for the HL group.

\section{Results}

A higher degree of HL was associated with less likelihood of having a driver's license. However, individuals with HL who had a driver's license, drove as much as NH drivers. HL was related to the criteria for choosing the type of transport, such that individuals with more HL rated written information as more important and time cost and safety as less important than those with less HL. However, in the aggregate, no difference between the groups could be shown in the distribution of how much each mode of transportation was used. 
With a few exceptions, HL did not affect the ratings of importance of hearing for different transportation types. The exceptions were walking and public transportation, where respondents with moderate HL rated hearing as significantly more important than those with NH. There was no effect of HL on involvement in incidents or accidents.

Degree of HL was related to several questions of driving ability, and the general pattern was that individuals with a higher degree of HL rated driving ability less affected by HL. This indicates that they might be using compensatory strategies. The interest in a warning system for inattention and the attitude toward strengthening of or complementing auditory information in traffic situations was high regardless of HL.

\section{Conclusions}

From this study, it was concluded that HL influences the prevalence of a driver's license and criteria for choosing type of transportation; however, HL has no effect on the distribution of how much each type of transportation was used. In general, respondents with more HL were less concerned about the effect of HL, indicating that they might be using compensatory strategies (adjustments to compensate for a decline). The interest in a warning system for inattention and the attitude toward strengthening of auditory information in traffic situations was high regardless of HL or not. This suggests a need for further research on compensatory strategies and on the design of support systems accessible for drivers with HL.

\section{Study 2: A driving simulator study}

\section{Purpose}

A simulator study was conducted to compare the effect of cognitive workload in individuals with and without HL, respectively, in driving situations with varying degree of complexity. The effectiveness of a tactile signal used to call for driver attention was also evaluated.

\section{Method}

Twenty-four participants with moderate $\mathrm{HL}$ and 24 with $\mathrm{NH}$ experienced 3 different driving conditions: baseline driving on a $35-\mathrm{km}$ long rural road with a speed limit of $70 \mathrm{~km} / \mathrm{hr}$; critical events with a need to act fast; and a parked car event with the possibility to adapt the workload to the situation (e.g., by deciding whether or not to focus on the secondary task). A secondary task (observation 
and recalling of 4 visually displayed letters) was present during the drive, with 2 levels of difficulty in terms of load on the phonological loop.

A tactile signal, presented by means of a vibration in the seat, was used to announce the secondary task and thereby simultaneously evaluated in terms of effectiveness when calling for driver attention. The letters were displayed on a screen at a low down angle, so that the driver had to look away from the road. Twice per minute, drivers were prompted by the tactile signal in the seat to first look at and then read back a complete sequence of 4 letters appearing on the display. The total duration of the task corresponds to a critical situation in which drivers take their eyes off the road to look at the display.

For the critical events, to create near collisions, the drivers were distracted by means of the secondary task, and then "pushed" across the median toward an oncoming vehicle by introducing a steering angle in the simulated vehicle without submitting this information to the motion platform. The parked car event was a situation when the participants saw a parked car ahead (from 360 meters) with warning lights activated. This study generated 2 papers with different focus presented separately below.

\section{Paper II: Cognitive workload and driving behavior in persons with hearing loss}

In this paper, objective driver behavior measures from the simulator study accompanied by subjective ratings during and after the test drive are presented, as well as the result from secondary task and the questionnaire after driving.

\section{Method}

Driver behavior measures were mean driving speed; SD of Driving speed; mean LP; SD of LP; and minimum time to line crossing. The secondary task was analyzed with respect to the number of correct recalled letters per task, number of skipped letters per task, and number of correct recalled letters per task ignoring the order. Subjective ratings during and after the test drive were included to evaluate the realism of the simulated event. There was also a questionnaire after driving including self-reported driving behavior, realism of the simulator, and evaluation of the tactile signal used to announce the secondary task.

\section{Results}

HL had no effect on driving behavior during baseline driving, where no events occurred. During both the secondary task and the parked car event, HL was associated with decreased mean driving speed compared with baseline driving. 
Participants with HL drove approximately $6 \mathrm{~km} / \mathrm{hr}$ slower during the secondary task than NH participants did (approx. $65 \mathrm{~km} / \mathrm{hr}$ vs. $70 \mathrm{~km} / \mathrm{hr}$ ), F(1, 44) = 7.68, p $=0.01, \eta \mathrm{p} 2=0.14$. At the parked car event, participants with $\mathrm{HL}$ drove approximately $5 \mathrm{~km} / \mathrm{hr}$ slower, $\mathrm{F}(1,44)=2.42$, $\mathrm{p}=0.05$, $\eta \mathrm{p} 2=0.05$.

The effect of HL on the secondary task performance, both at baseline driving and at critical events, was more skipped letters and fewer correctly recalled letters. Furthermore, at critical events task difficulty affected participants with HL more. There was no effect of HL on the secondary task at the parked car event. Participants were generally positive about the use of a tactile signal in the seat as a means for announcing the secondary task. There was no effect of HL on self-reported driving performance.

\section{Conclusions}

It was concluded that differences in driving behavior and secondary task performance related to HL appear when demands increase, either when driving demands exceed baseline driving or when the secondary task becomes more cognitively demanding or both. Increased demands lead to a more cautious driving behavior with a decreased mean driving speed and less focus on the secondary task. This indicate that HL is associated with both compensatory strategies and coping strategies. Seat vibration was found to be a feasible way to alert drivers with or without HL.

\section{Paper III: Cognitive workload and visual behavior in elderly drivers with hearing loss}

The objective of this paper was to compare visual behavior in individuals with $\mathrm{NH}$ and with moderate HL, and reveal possible differences by analyzing eyetracking data from the simulator study.

\section{Method}

The cockpit was divided into 7 target zones: windshield, right, left, center mirror, speedometer, task display, other. Gaze data were analyzed with respect to distribution of glances, fixations in target zones and eye movement behavior. Eye gaze behavior was assessed during normal driving and driving with the loading secondary task. The following performance indicators were used: number of glances away from the road, mean duration of glances away from the road, maximum duration of glances away from the road, and the percentage of time when the driver was looking at the road. During the secondary task, additional eye movement data were assessed in terms of number of glances to the 
secondary task display, mean duration of glances to the secondary task display, and maximum duration of glances to the secondary task display.

\section{Results}

Vertical and horizontal gaze directions showed only small differences between the NH and HL groups, such that the HL group tended to have narrower and more distinct gaze manners corresponding to the speedometer and the mirrors in the cockpit. There were also some indications that, during the secondary task, the HL group looked in the center rear-view mirror and further to the right more often than the $\mathrm{NH}$ group. Also, it could be seen that glances toward the secondary task display were preceded by glances to the mirrors more often in the HL group than in the NH group.

The main result from the analysis of target zones (the objects that the driver looks at within the car's cockpit) was that during the secondary task, drivers with HL looked twice as often in the rear-view mirror as they did during normal driving and twice as often as drivers with NH regardless of the driving condition.

Also, during secondary task, drivers with HL showed a different strategy when looking away from road. They looked away from the road as much as drivers with $\mathrm{NH}$; however, with more frequent glances of shorter duration.

\section{Conclusions}

It was concluded that differences in visual search behavior between drivers with $\mathrm{NH}$ and drivers with HL are bound to driving condition. During the secondary loading task, drivers with HL looked twice as often in the rear-view mirror than during normal driving and than drivers with $\mathrm{NH}$, regardless of driving condition. Moreover, during secondary task, drivers with HL looked away from the road as much as drivers with $\mathrm{NH}$, but with more frequent glances of shorter duration. The results also indicate that drivers with HL performed a visual scan of the surrounding traffic environment before looking away toward the secondary task display. This more active visual search behavior might indicate that drivers with HL use compensatory strategies to a higher extent than NH drivers. 


\section{Study 3: A field study in real traffic}

\section{Paper IV: Hearing loss and a supportive tactile signal in a navigation system: effects on driving behavior and eye movements}

\section{Purpose}

The purpose of the third study, conducted in real traffic, was to replicate and further examine findings from previous simulator study, namely driver compensatory strategies associated with HL and evaluate possible effects of additional tactile support in a navigation system. Furthermore, since the simulator study indicated differences in gaze behavior between drivers with and without HL, eye-tracking data was analyzed as part of the study

\section{Method}

Thirty-two participants (16 HL and $16 \mathrm{NH}$ ) performed two pre-programmed navigation tasks in an urban environment. In one task, participants received only visual navigation information, while in the other vibration in the seat was used as a complement. This tactile support was given in the left or the right side of the driver's seat to indicate the direction of the next turn. Performance indicators and measures included driving speed, driving behavior observations (using a protocol filled out by a test leader), eye tracking, and a post-drive questionnaire. SMI glasses were used for eye tracking, recording the point of gaze within the scene. Analysis of gaze data was performed on predefined regions such as windscreen, mirrors, navigation display, and speedometer. The questionnaire examined participants' experience of the two navigation tasks in terms of their feelings of safety, usefulness, and comfort.

\section{Results}

On road sections with a speed limit of $70 \mathrm{~km} / \mathrm{hr}$, participants with a HL drove 4 $\mathrm{km} / \mathrm{hr}$ slower than participants with $\mathrm{NH}$. The same tendency was also seen on sections with a speed limit of $50 \mathrm{~km} / \mathrm{hr}$; however, this result was not statistically significant.

During observed driving, participants with $\mathrm{NH}$ had on average 0.3 more marks on the measure 'speed too high' than participants with HL, and participants with HL had 0.5 more marks on the measure 'speed too low' than those with NH. Participants with HL also averaged 1 mark higher on the measure 
'uneven speed' than participants with NH. Participants with HL spent on average $1.4 \%$ more time looking in the rear-view mirror than $\mathrm{NH}$ participants. HL participants looked an average of 3 times as often ( 0.3 times per minute vs. 0.1 times) in the rear-view mirror as the $\mathrm{NH}$ group, but there was no effect on the duration of glances.

When driving without the tactile information activated, participants had on average 0.5 more marks on the measure 'inattention straight' and 0.5 more marks on the measure 'position distance' than when they had the tactile information. With the tactile information activated, participants looked on average $7 \%$ less at the navigation display and consequently on average $7 \%$ more through the windscreen than without the tactile information. The number of glances per minute revealed that without the tactile information, on average participants looked once more per minute at the navigation display and there was no effect on the duration of glances. With the tactile information activated, both hearing groups were significantly more satisfied with their ability to navigate and with the help they got from the system. Participants also felt safer and more comfortable in this condition. Furthermore, participants in the HL group were significantly more satisfied than the NH group with their ability to navigate when the tactile information was activated. There was no effect of HL on selfrated driving performance.

\section{Conclusions}

Results from this study revealed that drivers with HL drove more slowly than drivers with $\mathrm{NH}$, drove slower and looked more often in their rear-view mirror. These compensatory strategies suggest a more cautious driving behavior. The study also showed that tactile support leads to higher satisfaction with the navigation system, less time spent looking at the navigation display (in terms of frequency), and thus more focus on the road and better driving performance (in terms of both attention and distance). 


\section{General discussion}

The general aim of this thesis was to investigate traffic safety and mobility for older individuals with HL from the perspective of cognitive psychology. With the limited previous research and relatively low level of knowledge in this field the approach has been exploratory with subjective and objective performance indicators, and the findings from each study have been included for further evaluation.

The questionnaire survey investigated how HL affects the choice of transportation, personal views of HL in relation to transport situations, and the design requirements for driver support systems accessible for road users with HL. The simulator study examined differences in driving behavior and visual behavior between drivers with $\mathrm{NH}$ and drivers with $\mathrm{HL}$ and the effectiveness of a tactile signal to alert drivers. The field study further examined possible compensatory strategies associated with HL, the usefulness of an additional tactile support in a navigation system, and differences in eye movement patterns.

\section{Summary of results}

Summarizing and abstracting the effects of HL throughout the studies included in this thesis reveal that the effects of HL on traffic safety and mobility are existing, but small (in terms of effect sizes), often bound to workload condition and rather specific, but still consistent in the replicated studies.

The questionnaire revealed that differences in transportation habits related to HL include the less likelihood of having a driver's license and a higher valuing of written information, with the latter possibly prioritized before time and safety issues. Moreover, respondents with more HL were less concerned about the effect of HL, indicating that they might be using compensatory strategies. In addition, the interest in a warning system and the attitude toward strengthening of or complementing auditory information in traffic situations was high regardless of hearing ability. These are all new findings, pointing to a few potentially important effects of HL from a traffic safety and mobility perspective. 
Furthermore, the questionnaire revealed that HL was not related to the frequency of using any of the transportation types (e.g., cars, cycling, or public transportation). There was no difference in the patterns with regard to transportation types during wintertime or any effect of HL on self-reported incidents or accidents.

In the experimental studies, differences related to HL in terms of driving behavior (mostly lower driving speed) were bound to driving conditions and occurred when the complexity of driving task increased (simulator study) or at a higher speed limit (field study). There was also an effect of HL on visual behavior, indicated in the simulator study and confirmed in the field study. Drivers with HL had a more active visual behavior with more frequent glances on the secondary task (simulator study), more frequent glances in the rear-view mirror, and more general scanning of the environment before looking away from the road (simulator study). Secondary task performance was lower for the HL group, with more skipped letters, suggesting this group is less willing to perform this task. These are all new findings, in line with the expectations, and the effect of HL on driving behavior and on visual search behavior suggest people with HL use more compensatory strategies and coping strategies leading to a more cautious driving behavior.

The tactile signal in the driver seat was found useful in both experimental studies, both for driver attention and for facilitating navigation with a GPS navigation device. The field study showed that the tactile support led to higher satisfaction with the navigation system. The tactile support also led to less time spent looking at the navigation display, and thus more focus on the road and better driving performance in terms of both attention and distance. These are new findings, supporting the expectations and adding to the growing body of evidence of the benefits of using tactile information in cars (van Erp \& van Veen, 2004; Ho, Tan, \& Spence, 2005; Ho, Reed, \& Spence, 2006).

In the simulator study (study II), HL had no effect on driving behavior at baseline driving, where no events occurred and when no secondary task was present. In the field study, the effect of HL on driving speed displayed the same pattern, however was not significantly lower, at the lower speed limit. In neither of the experimental studies, there was an effect of HL on the self-rated driving performance.

\section{Choice of transportation}

ICF, conceptualizing functioning and disability as an interaction between an individual's health condition, contextual factors of the environment and personal factors, includes mobility in activity and participation (WHO, 2001). There were 
some effects of HL found, which according to the hierarchical model suggested by Michon (1985), belong to the top level, where strategic decisions are made by control processing such as the choice of type of transport.

That the likelihood of having a driver's license is negatively associated with the degree of HL is a new finding. There was no effect of HL on mileage and also no relation between the degree of HL and driving cessation. This suggests that in the studied population difficulties or lack of interest associated with HL and car driving emerge when deciding whether or not to learn to drive. This is an indication of individuals with HL using coping. Knowing that difficulty in taking part in activities increase with the degree of HL (Gopinath, Schneider, Hickson, et al., 2012a; Grue et al., 2009; Wallhagen et al., 2001; Schneider et al., 2010), one could speculate that taking driving lessons might be too difficult for some individuals with HL, as some respondents mentioned. The main focus in this thesis is on those with moderate HL who are still driving; however, this driver's license issue is something for further research, since car access can act as a compensational tool for functional limitations (Sirén \& Hakamies-Blomqvist, 2004, 2009) and is associated with better health and well-being among the elderly (Ellaway, Macintyre, Hiscock, \& Kearns, 2003; Macintyre, Hiscock, Kearns, \& Ellaway).

That individuals with HL sometimes find written information more important than time cost, and safety issues is also a new finding. According to Rumar (1988), there is always a risk in being mobile, and risk can be divided into statistical and experienced risk. There is a possibility that individuals with HL feel safer when they have written information and therefore prioritize this before statistical safety and time cost. Furthermore, individuals with moderate HL expressed a higher need to be able to hear on public transportation than those with NH. This is in line with Gopinath et al. (2012), who found that using public transportation is harder for individuals with HL, and there might be a need for more written information on public transportation to increase experienced safety, activity and participation for individuals with HL.

\section{Driving behavior}

Motivational driving behavior models all have in common maintenance of the acceptable level of risk (Wilde, 1982; Fuller \& Santos, 2002; Fuller, 2005, 2007; Fuller et al., 2008; Fuller, McHugh et al., 2008; Vaa et al., 2000; Vaa, 2003, 2007, 2011; Näätänen \& Summala, 1974). Consistent with results from Wu et al. (2014), effects on driving behavior for individuals with HL emerge when driving task exceeds baseline driving. The main effects from the simulator study are consistent with Fuller (2005), suggesting that manipulating driving speed and 
engagement in a secondary tasks are the primary mechanisms for maintaining the preferred level of difficulty.

Lewis-Evans (2012) concluded that speed is not only a conscious choice but rather a challenge to be handled, at least on some level, by automatic processes, and that the existence of these processes can be inferred when the cognitive capability of drivers is loaded. There is a higher risk of cognitive fatigue in individuals with HL, and also possibly a different perception of speed (cf. Evans, 1970; Ohta \& Komatsu, 1991). Taking this together, there is a possibility that drivers with HL may have decreased speed control, and therefore drive slower and at a more uneven speed (field study).

In addition, considering Lewis-Evans' (2012) suggestion that there is a threshold to account for the perception of subjective variables (e.g., task difficulty, effort, comfort, crash risk, and feeling of risk), drivers with HL might experience an increased feeling of risk (Rumar, 1988) and therefore aim to maintain a different level of risk. This increased feeling of risk might come from a decreased perception of the surroundings and decreased feedback leading to a decreased feeling of control, which is also reflected in the gaze behavior. That is, they might compensate for the increased risk by driving at a lower speed (e.g. Haustein et al., 2013), and be less engaged in distracting activities, which is a coping strategy (e.g., Ben-Zur, 2009; Fofanova \& Vollrath, 2012).

\section{Visual behavior}

Drivers with HL showed more watchful manners with regard to visual behavior. The higher frequency of glances in the mirrors point to the fact that individuals with HL might value this kind of information more than those with NH. This new finding is in line with the expectations of a compensatory strategy with a more active visual search behavior, due to the fact that hearing gives us valuable spatial and temporal resolution. This is also in line with Wilson and Eggemeier (1991), who found a relationship between frequency of fixation and instrument importance, and this, might be a part of a compensatory behavior.

Visual search strategy is according to traffic inspectors the most important concept related to risk awareness (Lidestam et al., 2010). The difference between drivers with HL and drivers with $\mathrm{NH}$ in the strategy of looking away from the road was apparent during the secondary task in the driving simulator. Drivers with HL looked away more often and for a shorter period each time; however, there was no effect of HL on total time with the eyes off the road. Again, this behavior might be connected to the experienced safety and feeling of risk, suggesting that avoiding long glances away is a coping strategy on the part of those with HL. 
With the descriptive and explorative approach of this thesis, the relationship between the secondary task performance in Paper II and the gaze behavior in Paper III is interesting. In Paper II, we concluded that drivers with HL might be less willing to make an effort to perform the secondary task. Their lower performance might also be due to the fact that the task loads on the phonological loop and is thus more cognitively demanding for drivers with HL. An acquired HL may lead to a deteriorated function in the phonological loop, which means that drivers with HL should need to look at the letters for a longer time. However, as seen in Paper III, on the contrary they look at the secondary task display more frequently and with shorter duration compared to drivers with $\mathrm{NH}$. This indicates that with the limited capacity during the secondary task, which also results in decreased speed for drivers with HL, driving safety is prioritized before performance on the task, which could be a sign of compensatory behavior.

\section{Driver assistance systems}

In the questionnaire survey, the interest in driver assistance systems was not affected by HL and suggested evaluation of alternative modality for driver support systems. From the classifications suggested by Carsten and Nilsson (2001), the HMI aspect (operating and communicating with the system) and the traffic safety aspect (system influence on driving behavior, including changes in interactions with other road users) are relevant for evaluating the effect of HL. Concerning the HMI aspect, and in line with the expectations and previous findings (e.g. van Erp \& van Veen, 2004;), the tactile signal in the driver's seat was useful in both experimental studies, for both calling for driver attention and facilitating navigation with a GPS device. Furthermore, of high relevance for the traffic safety aspect, regardless of hearing status, the tactile support led to higher satisfaction with the navigation system, less time spent looking at the navigation display, more focus on the road, and better driving performance. This was in line with the expectations too, and may increase traffic safety for drivers regardless of HL or not, since this may release other heavily loaded sensory channels (c.f. Wickens and Hollands, 1999) and therefore potentially provide a major safety enhancement.

\section{Methodological discussion}

The advantages of performing a simulator study also come with limitations (Mullen, Charlton, Devlin, \& Bédard, 2001; Nilsson, 1993). For example, motion, velocity and acceleration ranges are limited, it is impossible to fully represent a real traffic environment, and participants may suffer from simulator 
sickness, a type of motion sickness experienced only in simulators (Nilsson, 1993).

There was an effect of $\mathrm{HL}$, such that drivers with $\mathrm{NH}$ experienced the simulator as more realistic. Also, some effects of eye movement behavior indicated in the simulator were confirmed in the field study. These two effects might be related, such that the realism was needed for some of the effects to show. Also, female drivers with HL reported the highest values of simulator sickness, which might be connected to the realism of the simulator, such that higher experienced realism lead to less simulator sickness.

Age-related HL is the most common type of $\mathrm{HL}$ and thus it is most relevant to look at the effects of HL in the group of older people. With a quasiexperimental design (HL vs. NH) follows a heterogeneity between groups. To create as homogenous groups as possible, apart from hearing status, the aim was to recruit participants under 65 years of age to avoid age effects. 


\section{Conclusions}

From the studies included in this thesis, it can be concluded that there are effects of HL on both traffic safety and mobility, such that individuals with HL are less likely to have a driver's license, more likely to show a more cautious driving behavior, and will sometimes prioritize experienced safety before statistical safety. The effects of HL revealed in this thesis are new findings and add to the knowledge and understanding of the influence of HL on traffic safety and mobility. Differences found consistently point to a generally more cautious behavior, which suggests an effect of HL on experienced safety.

Compensatory strategies and coping strategies associated with HL are bound to driving complexity and appear when complexity increases. These strategies include driving at lower speeds, using a more comprehensive visual search behavior (compensatory) and being less engaged in distracting activities (coping).

The influence of HL on the choice to drive a car is limited to the decision of whether or not to learn to drive, since HL does not affect mileage or driving cessation.

Evaluation of a tactile signal suggests that by adding a tactile modality, some driver assistance systems can also be made accessible to drivers with HL. At the same time, the systems might be more effective for all users, since visual resources can be more focused on the road, which could generally increase both traffic safety and mobility.

Based on the results in this thesis, drivers with HL cannot be considered an increased traffic safety risk, and there should be no need for adjustments of the requirements of hearing for a license to drive a car. 


\section{Suggestions for future research}

This thesis presents exploratory and experimental research on the effects of HL on traffic safety and mobility. Some effects of HL have been found (suggesting a more cautious driving behavior), which can be used in future recommendations. There are also some aspects worth looking into further. Generally, it is possible that individuals with disabilities (of different kinds) might contribute to a better understanding of how to design better driver support systems. Since they are more sensitive to higher workload, they might be able to indicate how to develop support systems, which might be more useful for all drivers.

The compensatory strategies found, indicating maintenance of a different level of difficulty, suggest further investigation of the effect of HL on feeling of risk.

The possibility of individuals with HL experiencing higher safety when there is written information and therefore prioritizing this before statistical safety and time cost is worth further evaluation.

The accessibility of written information on public transportation is relevant to evaluate, since differences appeared in this and other studies (Gopinath et al., $2012 b)$ related to the degree of HL.

Less likelihood of having a driver's license suggests further evaluation of the driving lesson situation for individuals with HL.

Positive effects of tactile signals in driver assistance systems suggest further research on how to implement accessible signals in these systems.

The effect of the use of hearing aid technologies when driving should be further investigated. This was not included in the studies presented in this thesis although there is reason to believe that the right aid can increase traffic safety and mobility (e.g., McCloskey, Koepsell, Wolf, \& Buchner, 1994; Wu et al., 2014).

The fact that there is a decline in various abilities (e.g., cognitive, visual, auditory) associated with normal aging, makes further examination of the effects of decline in each type and combination of types, and also the effects of aid for each type, relevant for future study.

The effects of HL on perception and decision-making has not been examined explicitly in studies presented in this thesis. However, the results pointing at a 
difference in experienced safety associated with HL suggest that these aspects should be further studied.

The studies included in this thesis focus on age-related HL. It would be of interest to look at the effects of other types of HL such as genetic deafness or individuals with $\mathrm{CI}$.

It would be relevant to study the effects of HL on cognitive fatigue and of cognitive fatigue on traffic safety, since cognitive fatigue is a known effect of HL (e.g. Moradi et al., 2014; Rönnberg et al., 2013) and could lead to decreased attention. Also, studying the effect of reducing cognitive fatigue on traffic safety can add to the understanding of the problem.

In this field of research, investigation into specific effects of decline in different aspects of EF, rather than attention to the broad perspective, is more likely to yield a more comprehensive picture.

It could be worthwhile to study other modalities of driver assistance systems than auditory and tactile, such as ambient (light), and to evaluate which modalities and ways of presenting the information are most suitable to which driver group or in which situations. 


\section{Acknowledgements}

Many people contributed to this work in many different ways and made the $\mathrm{PhD}$ journey possible, more solid, or simply more enjoyable. I want to express my greatest thanks to:

All the wonderful participants, who took part in my studies, shared your ideas, and showed your great interest in my work.

My boss Jan Andersson, the coaching master, for making this possible. You liked this idea from the start and you have supported me all the way with your positive attitude and enthusiasm.

Björn Lyxell, my main supervisor. Your professional way of restricting the study population and guiding me towards sensible frames was invaluable, as were your friendly phone calls just to check on how things were going. I also appreciate how you led me through the funding jungle, resulting in 4 great months in Australia for me and my family.

Björn Peters, who was concerned that co-supervising me would affect our friendship. Well, I was not concerned at all, and I believe I was right. You showed great generosity in inviting me to and inspiring me in your area of expertise, which is one of the main reasons I enjoy working with you. I am also grateful for your establishment of national and international contacts for me.

Björn Lidestam, my co-supervisor. Although you often expressed doubts about your own contribution to this work, I have always appreciated your involvement. You have the ability to recognize the most essential and most interesting results and a remarkable way of un-complicating things by breaking them down to pieces. I look forward to working more with you now that you have joined our group.

Louise Hickson, for your positive response to my query on visiting you as a guest PhD student. Thanks to you, Joanne Wood, Alex Black, and Alicja Malicka, my time at QUT and UQ in Brisbane was both enlightening and enjoyable. I look forward to future collaborations between our groups. 
I am fortunate to work at an institute where people are professional, friendly, and truly helpful. Lena Nilsson, you are the one who first hired me and recommended me to the ergonomics course, and this was crucial in the decisions that led me to where I am now. Jonas Jansson, you handed over a simulator project to me at a perfect time and this allowed me to collect a great amount of data in a short time, resulting in 2 published papers. Christer Ahlström, co-writer and dedicated data analyst, I appreciate your efficient and exemplary way of working, whether with study planning, data processing, or writing. Olle Eriksson, co-writer and statistics expert, I am grateful for your never-ending patience with my statistics questions and your good collaboration on Paper III. Thanks are also due to many colleagues, who with their expertise have all contributed in some valuable way to the studies: Anders Andersson, Jonas Andersson Hultgren, Björn Blissing, Anne Bolling, Anders Genell, Per Henriksson, Kristina Kindgren, Lena Levin, Katarina Nestor, Beatrice Söderström, Gunilla Sörensen, Harry Sörensen.

During my years at VTI, I have met some of my best friends. Sara Nygårdhs, thank you for simply being the genuine you. Katja Kircher, regardless of how busy you are, you always find the time to stay updated on and support my activities. Magnus Hjälmdahl, Jessica Berg, and Therese Jomander, the chats we have during lunch, coffee breaks, and between breaks are invaluable and the first thing I miss when I am away. Jerker Sundström, thank you for this advise: if you ever go for a $\mathrm{PhD}$, chose a subject that really interests you. Malin Eliasson, I have always appreciated your rationality and never-ending energy.

I am grateful for the colleagues that I got to know at the Disability Research Division and HEAD graduate school. Specifically, I want to thank Håkan Hua, for being a good friend through this journey and also for sharing your knowledge on Audiology; Jakob Dahl, for our interesting discussions on any topic; Claes Möller, for good and recurring email discussions on balance and motion sickness; Shahram Moradi for sharing your knowledge on cognitive fatigue; Malin Wass, for sharing your experience on how to apply for grants and go to Australia; Mary Rudner, for your guidance through the special research project - definitely my best course, and Maria Hugo Lindén for your fine administrative help, including organizing ticket and room bookings for courses located in other cities.

I have met many helpful people here and there to whom I want to express my thanks: Birgitta Larsby for lending me equipment, sharing your knowledge on audiology and helping me with participant recruitment. I am looking forward to more collaborations with you!; Therese Bohn Eriksson and Henrik Lindgren and the audiology clinics in Linköping and Norrköping for providing audiograms on the recruited participants; HRF, and in particular Jan-Olof Bergold, Diego Hedman, and Lautaro Aranda, for your cooperation with participant recruitment and input on the questionnaire; Kenneth Holmqvist for 
lending me the eye-tracking equipment, sharing your knowledge, and cooperating so helpfully in the field study, Nicholas Herbert for good teamwork in the field study. I hope we get a chance to work together again in the future, and the father of WM, Alan Baddeley, for responding so quickly and helpfully to my email with a question about display time.

A big thank you to my near and dear ones, my family and friends, for being my source of energy. You all know who you are and that I love to have you around! Among these, a special thanks to Mum and Dad, for always believing in me, and being constantly supportive but never intrusive, and to my cousin Mattias, for your great interest in what I am doing and your instant support in the English language.

Finally, my wise and loving husband Tobias. Thank you for being just the way you are. My favorite person. I love you. 


\section{References}

Andersson, U. (2002). Deterioration of the phonological processing skills in adults with an acquired severe hearing loss. European Journal of Cognitive Psychology, 14(3), 335-352.

Andersson, U., \& Lyxell, B. (1999). Phonological deterioration in adults with an acquired severe hearing impairment. Scandinavian Audiology, 28(4), 241-247.

Andersson, U., Lyxell, B., Rönnberg, J. \& Spens, K.-E. (2001). Cognitive correlates of visual speech understanding in hearing-impaired individuals. Journal of Deaf Studies and Deaf Education, 6, 103-116

Arlinger, S. (2003). Negative consequences of uncorrected hearing loss - a review. International Journal of Audiology, 42(2), 17-20.

Arlinger, S. (Ed.) (2007). Nordisk Lärobok i Audiologi [Nordic textbook of audiology]. Bromma: C-A Tegnér AB.

Atkinson, R.C., \& Shiffrin, R.M. (1968). Human memory: a proposed system and its control processes. In K.W. Spence \& J.T. Spence (Eds), The psychology of learning and motivation (Vol 2). New York: Academic Press. pp. 89-195.

Ausmeel H. (1988). TIPS (Text-Information-Processing-System): A user's guide. Linköping, Sweden: Department of Education and Psychology, Linköping University.

Baddeley, A. (2012). Working memory: theories, models, and controversies. Annual Revue of Psychology 63, 1-29.

Baddeley, A. D. (1968). How does acoustic similarity influence short term memory? Quarterly Journal of Experimental Psychology, 20, 249-264.

Baddely, A. (2000). The episodic buffer: a new component of working memory? Trends in Cognitive Sciences, 4(11), 417-423.

Baddeley, A. (1983). Working memory. Philosophical Transactions of the Royal Society, 302, 311-324.

Ball, K., \& Owsley, C. (1993). The Useful Field of View Test: a new technique for evaluating age-related declines in visual function. Journal of the American Optometric Association, 64(1), 71-79.

Ball, K., Owsley, C., Sloane, M.E., Roenker, D.L., \& Bruni, J.R. (1993). Visualattention problems as a predictor of vehicle crashes in older drivers. Investigative Ophthalmology \& Visual Science, 34(11), 3110-3123.

Ball, K., Owsley, C., Stalvey, B., Roenker, D.L., Sloane, M.E., \& Graves, M. (1998). Driving avoidance and functional impairment in older drivers. Accident Analysis \& Prevention, 30, 313-323. 
Baltes, P.B. \& Lindenberger, U. (1997). Emergence of a powerful connection between sensory and cognitive functions across the adult life span: a new window to the study of cognitive aging? Psychology and Aging, 12, 12-21.

Banister, D., \& Bowling, A. (2004). Quality of life for the elderly: the transport dimension. Transport Policy, 11(2), 105-115.

Ben-Zur, H. (2009). Coping styles and affect. International Journal of Stress Management, 16(2), 87-101.

Bishop, C.M. (2006). Pattern recognition and machine kearning. New York: Springer-Verlag.

Bonnel, W. (1999). Giving up the car: older women's losses and experiences. Journal of Psychosocial Nursing and Mental Health Services, 37, 10-15.

Bopp, K.L., \& Verhaeghen, P. (2005). Aging and verbal memory span: a metaanalysis. Journals of Gerontology Series B - Psychological Sciences and Social Sciences, 60(5), 223-233.

Bowles, R.P., \& Salthouse, T.A. (2008). Vocabulary test format and differential relations to age. Psychology and Aging, 23(2), 366-376.

Brayne, C., Dufouil, C., Ahmed, A., Dening, T.R., Chi, L-Y., McGee, M., \& Huppert, F. A. (2000). Very old drivers: Findings from a population cohort of people aged 84 and over. International Journal of Epidemiology, 29(4), 704707.

Brookhuis, K.A., Waard, D.D., \& Fairclough, S.H. (2003). Criteria for driver impairment. Ergonomics, 46(5), 443-445.

Brickman A.M., \& Stern Y. (2009). Aging and memory in humans. In: L.R. Squire (Ed.) Encyclopedia of Neuroscience (Vol. 1) Oxford: Academic Press. pp. 175180.

Carsten, O., \& Nilsson, L. (2001). Safety assessment of driver assistance systems. European Journal of Transport and Infrastructure Research, 1(3), 225-243.

Carver, C.S., \& Connor-Smith, J. (2010). "Personality and Coping”. Annual Review of Psychology, 61, 679-704.

Catchpole, K., \& McKeown, D. (2007). A framework for the design of ambulance sirens. Ergonomics, 50(8), 1287-1301.

Cerella, J. (1990). Aging and information-processing rate. In: J.E. Birren, \& K.W. Schaie (Eds.), Handbook of the psychology of aging, 3rd ed. San Diego, CA: Academic Press, pp. 201-221.

Charlton, J.L., Oxley, J., Fildes, B., Oxley, P., \& Newstead S. (2003). Selfregulatory behaviours of older drivers. Annual Proceedings Advancement of Automotive Medicine, 47, 181-194.

Chipman, M.L., MacGregor, C.G., Smiley, A.M., \& Lee-Gosselin, M. (1992). Time vs. distance as measures of exposure on driving surveys. Accident Analysis \& Prevention, 24(6), 679-684.

Classon, L. (2013) Phonological decline and compensatory working memory in acquired hearing impairment. Doctoral Dissertation. The Swedish Institute for Disability Research. Linköping University. 
Clay, O.J., Edwards, J.D., Ross, A.L., Okonkwo, O., Wadley, V.G., Roth, D.L., \& Ball, K.K. (2010). Visual function and cognitive speed of processing mediate age-related decline in memory span and fluid intelligence. Journal of Aging Health, 21(4): 547-566.

Conrad, R., \& Hull, A.J. (1964). Information, acoustic confusion and memory span. British Journal of Psychology, 55, 429-437.

Conway A.R., Kane M.J., \& Engle R.W. (2003). Working memory capacity and its relation to general intelligence. Trends in Cognitive Sciences, 7(12): 547-552.

Craik, F.I.M., \& Salthouse, T.A. (2000). The handbook of aging and cognition (Second ed.). London: Lawrence Erlbaum Associates.

D’Ambrosio, L.A., Donorfio, L.K.M., Coughlin, J.F., Mohyde, M., \& Meyer, J. (2008). Gender differences in self-regulation patterns and attitudes toward driving among older adults. Journal of Women \& Aging, 20(3-4), 265-282.

Daneman, M. \& Carpenter, P. (1980). Individual differences in working memory and reading. Journal of Verbal Learning and Verbal Behavior, 19, 450-466.

Daneman, M. \& Merikle, P.M. (1996). Working memory and language comprehension: a meta-analysis. Psychonomic Bulletin and Review, 3, 422433.

De Lorenzo, R.A., \& Eilers, M.A. (1991). A review of emergency warning systems. Annals of Emergency Medicine, 20(12), 1331-1335

de Waard, D. (1996). The measurement of drivers' mental workload. Thesis. University of Groningen, Netherlands.

Dellinger, A.M., Kresnow, M., White, D.D., \& Sehgal, M. (2004). Risk to self versus risk to others: how do older drivers compare to others on the road? American Journal of Preventive Medicine, 26(3), 217-221.

Diamond, A. (2013). Executive functions. Annual Review of Psychology, 64, 135168.

Dillén, J., Schmidt, L., \& Jarlebring, I. (2005). Äldre personers resvanor och aktiviteter [Older adults' travel habits and activities]. Solna: Transek.

Dimitrijevic, A., John, M.S., \& Picton, T.W. (2004). Auditory steady-state responses and word recognition scores in normal-hearing and hearing-impaired adults. Ear and Hearing, 25, 68-84.

Donorfio, L.K.M., Mohyde, M., Coughlin, J., \& D'Ambrosio, L. (2008). A qualitative exploration of self-regulation behaviors among older drivers. Journal of Aging \& Social Policy, 20(3), 323-339.

Eachus, P., Cassidy, S., Norgate, S., Marrow, L., \& Greene, L. (2008). Internet selfefficacy and visual search strategies: the use of eye tracking technology in the development of web-based learning resources. Informing Science \& IT Education Conference. Varna, Bulgaria.

Edwards, J.D., Lunsman, M., Perkins, M., Rebok, G.W., \& Roth D.L (2009). Driving cessation and health trajectories in older adults. Journals of Gerontology Series A: Biological Sciences and Medical Sciences, 64(12), 1290-1295.

Ferris, F.L., Kassoff, A., Bresnick, G.H., \& Bailey, I. (1982). New visual acuity charts for clinical research. American Journal of Ophthalmology, 94, 91-96. 
Ellaway, A., Macintyre, S., Hiscock, R., \& Kearns, A. (2003). In the driving seat: psychosocial benefits from private motor vehicle transport compared to public transport. Transportation Research Part F: Traffic Psychology and Behaviour, 6, 217-231.

Elliott, E.M., Cherry, K.E., Brown, J.S., Smitherman, E.A., Jazwinski, S.M., Yu, Q., \& Volaufova, J. (2011). Working memory in the oldest-old: evidence from output serial position curves. Memory \& Cognition, 39(8), 1423-1434.

Endsley, M.R., \& Garland, D.J. (2000). Situation awareness analysis and measurement. London: Lawrence Erlbaum Associates.

Engle, R.W., Tuholski, S.W., Laughlin, J.E., Conway, A.R. (1999). Working memory, short-term memory, and general fluid intelligence: a latent-variable approach. Journal of Experimental Psychology: General 128(3), 309-31

Englund, L. (Ed.). (2001). Medicinska förhållanden av betydelse för innehav av körkort - Hörsel och balanssinne [Medical conditions of importance for obtaining a driving license]: Vägverket, Trafikmedicinska rådet

Evans, L. (1970). Speed estimation from a moving automobile. Ergonomics, 13(2).

Eysenck, M.W., \& Keane, M.T. (2010). Cognitive psychology: a student's handbook (6th ed.): East Sussex: Psychology Press.

Farquhar, M. (1995). Elderly people's definitions of quality of life. Social Science \& Medicine, 41(10), 1439-1446.

Fitzgibbons, P.J., \& Gordon-Salant, S. (2010). Behavioral studies with aging humans: hearing sensitivity and psychoacoustics In S.Gordon-Salant, R.D. Frisina, A. Popper, \& D. Fay (Eds.), The aging auditory system: Perceptual characterization and neural bases for presbyacusis. Berlin: Springer.

Fofanova, J., \& Vollrath, M. (2012). Distraction in older drivers -a face-to-face interview study. Safety Science, 50(3), 502-509.

Fonda, S.J., Wallace, R.B., \& Herzog, A.R. (2001). Changes in driving patterns and worsening depressive symptoms among older adults. Journals of Gerontology Series B: Psychological Sciences and Social Sciences, 56B(6), 343-351.

Forrest, K.Y.Z., Bunker, C.H., Songer, T.J., Cohen, J.H., \& Cauley, J.A. (1997). Driving patterns and medical conditions in older women. Journal of the American Geriatrics Society, 45(10), 1214-1218.

Frisina, D.R., \& Frisina, R.D. (1997). Speech recognition in noise and presbycusis: relations to possible neural mechanisms. Hearing Research, 106(1-2), 95-104.

Fuller, R. (2000). The Task Capability Interface Model of the driving process. Recherche Transports Sécurité, 66, 47-59.

Fuller, R. (2005). Towards a general theory of driver behaviour. Accident Analysis \& Prevention, 37(3), 461-472.

Fuller, R. (2007). Motivational determinants of control in the driving task. In: P. Cacciabue (Ed.), Modelling driver behaviour in automotive environments: critical issues in driver interactions with intelligent transport systems. London: Springer; pp. 165-188.

Fuller, R. (2011). Driver control theory: from task difficulty homeostasis to risk allostasis. In B. Porter (Ed.), Handbooks of Traffic Psychology. Waltham, MA: Academic Press. 
Fuller, R., Bates, H., Gormley, M., Hannigan, B., Stradling, S., Broughton, P., Kinnear, N., \& O'Dolan, C. (2008). The conditions for inappropriate high speed: a review of the research literature from 1995 to 2006. London: Department of Transport.

Fuller, R., McHugh, C., \& Pender, S. (2008). Task difficulty and risk in the determination of driver behaviour. Revue Européenne De Psychologie Appliquée/European Review of Applied Psychology, 58(1), 13-21.

Fuller, R., \& Santos, J.A. (2002). Psychology and the highway engineer. In R. Fuller, \& J.A. Santos (Eds.), Human factors for highway engineers. Bingley, UK: Pergamon.

Gabaude, C., Marquié, J., \& Obriot-Claudel, F. (2010). Self-regulatory behaviour in the elderly: relationships with aberrant driving behaviours and perceived abilities. Le Travail Humain, 73(1), 31-52.

Gabriel, Z., \& Bowling, A. (2004). Quality of life from the perspectives of older people. Ageing and Society, 24, 675-691.

Gagliardi, C., Marcellini, F., Papa, R., Giuli, C., \& Mollenkopf, H. (2010). Associations of personal and mobility resources with subjective well-being among older adults in Italy and Germany. Archives of Gerontology and Geriatrics, 50(1), 42-47.

Gibson, J.J., \& Crooks, L.E. (1938). A theoretical field-analysis of automobiledriving. The American Journal of Psychology, 51(3), 453-471.

Glad, A. (1977). Requirements regarding drivers: hearing ability. Oslo: Institute of Transport Economics.

Godthelp, J. (1984). Studies on human vehicle control. PhD Thesis, Soesterberg, The Netherlands: Institute for Perception, TNO.

Gopinath B., Schneider, J., McMahon, C.M., Teber, E., Leeder, S.R, Mitchell, P. (2012). Severity of age-related hearing loss is associated with impaired activities of daily living. Age and Ageing 41(2):195-200.

Gopinath, B., Schneider, J., Hickson, L., McMahon, C. M., Burlutsky, G., Leeder, S.R., \& Mitchell, P. (2012). Hearing handicap, rather than measured hearing impairment, predicts poorer quality of life over 10 years in older adults. Maturitas, 72(2), 146-151.

Gordon-Salant, S. (2005). Hearing loss and aging: new research findings and clinical implications. Rehabilitation Research and Development, 42(4), 9-23.

Gorman M. (1999) Development and the rights of older people. In: Randel, J., German, T., Ewing, D. (Eds.). The ageing and development report: poverty, independence and the world's older people. London: Earthscan Publications; pp $3-21$.

Grady, C. (2012). The cognitive neuroscience of ageing. Nature Reviews Neuroscience, 13(7), 491-505.

Granick, S., Kleban, M.H. \& Weiss, A.D. (1976). Relationships between hearing loss and cognition in normally hearing aged persons. Journal of Gerontology, 31(4), 434-440. 
Green, K.A., McGwin, G., \& Owsley, C. (2013). Associations between visual, hearing, and dual sensory impairments and history of motor vehicle collision involvement of older drivers. Journal of the American Geriatrics Society, 61(2), 252-257.

Groeger, J.A. (2000). Understanding driving: applying cognitive psychology to a complex everyday task. London: Routledge.

Grue, E.V., Schroll, M., Jónsson, P.V., Ranhoff, A.H., Noro, A., Finne-Soveri, H., Jonsén, E. (2009). Vision and hearing impairments and their associations with falling and loss of instrumental activities in daily living in acute hospitalized older persons in five Nordic hospitals. Scandinavian journal of Caring Sciences, 23(4), 635-643.

Gwyther, H., \& Holland, C. (2012). The effect of age, gender and attitudes on selfregulation in driving. Accident Analysis \& Prevention, 45, 19-28.

Hakamies-Blomqvist, L. (1994). Aging and fatal accidents in male and female drivers. Social Sciences, 49(6), 286-290.

Hakamies-Blomqvist, L., \& Wahlström, B. (1998). Why do older drivers give up driving? Accident Analysis \& Prevention, 30(3), 305-312.

Hardin, J.,\& Hilbe, J. (2003). Generalized estimating equations. London: Chapman and Hall/CRC

Hatakka, M., Keskinen, E., Gregersen, N.P., Glad, A., \& Hernetkoski, K. (2002).

From control of the vehicle to personal self-control; broadening the perspectives to driver education. Transportation Research Part F: Traffic Psychology and Behaviour, 5(3), 201-215.

Haustein, S., Sirén, A., Franke E., Pokrieke, E., Alauzet, A., Marin-Lamellet, C., Armoogum, J., O’Neill, D. (2013). Demographic change and transport. Final report of WP1:Consol.

Heyl, V., \& Wahl, H.W. (2012). Managing daily life with age-related sensory loss: cognitive resources gain in importance. Psychology and Aging, 27(2):510-521.

Hitch, G.J., \& Halliday, M.S. (1983). Working memory in children. Philosophical Transactions of the Royal Society of London: Series B, 302, 325-340.

Hicks, C.B., Tharpe, A.M. (2002). Listening effort and fatigue in school-age children with and without hearing loss. Journal of Speech, Language, and Hearing Research, 45, 573-584.

Hicks, T.G. \& Wierwille, W.W. (1979). Comparison of five mental workload assessment procedures in a moving-base driving simulator. Human Factors, 21(2), 129-143.

Hickson, L., Wood, J., Chaparro, A., Lacherez, P., \& Marszalek, R. (2010). Hearing impairment affects older people's ability to drive in the presence of distracters. Journal of the American Geriatrics Society, 58(6), 1097-1103.

Hjorthol, R., Levin, L. \& Sirén, A. (2010). Mobility in different generations of older persons. The development of daily travel in different cohorts in Denmark, Norway and Sweden. Journal of Transport Geography, 18(5), 624-633.

Ho, C., Reed, N., Spence, C. (2006). Assessing the effectiveness of "intuitive" vibrotactile warning signals in preventing front-to-rear-end collisions in a driving simulator. Accident Analysis and Prevention, 38, 988-996. 
Ho, C., Tan, H.Z., Spence, C. (2005). Using spatial vibrotactile cues to direct visual attention in driving scenes. Transportation Research Part F: Traffic Psychology and Behaviour, 8, 397-412.

Holland, C.A. (2009). The relationships between sensory and cognitive decline in older age. ENT \& Audiology News, 18(4), 94-95.

Holland, C.A., \& Rabbitt, P.M.A. (1992). People's Awareness of their age-related sensory and cognitive deficits and the implications for road safety. Applied Cognitive Psychology, 6(3), 217-231.

Hollnagel, E., Nåbo, A., \& Lau, I.V. (2003). A systemic model for driver-incontrol. Paper presented at the Second International Driving Symposium on Human Factors in Driver Assessment, Training and Vehicle Design. Utah, July 21-24.

Howard, C.Q., Maddern, A.J., \& Privopoulos, E.P. (2011). Acoustic characteristics for effective ambulance sirens. Acoustics Australia, 39, 2-43.

Hua, H. (2014). Employees with Aided Hearing Impairment: An Interdisciplinary Perspective. (Doctoral dissertation). Linköping: Linköping University Electronic Press.

Hughes, D., Sapp, G., and Kohler, M. (2006). Issues in the Intellectual assessment of hearing impaired children. ERIC Digest. Education Resources Information Center. Available online at: http://www.eric.ed.gov/ERICDocs/data/ericdocs2sql/content_storage_01/00000 19b/80/1b/f1/a4.pdf, pp 1-17. Accessed on September 25, 2014.

Hughes, P.K. \& Cole, B.L. (1988). The effect of attentional demand on eye movement behaviour when driving. In A.G. Gale, M.H. Freeman, C.M. Haslegrave, P. Smith \& S.P. Taylor (Eds.), Vision in vehicles-II (pp. 221-230). Amsterdam: North-Holland.

Hällgren, M., Larsby, B., Lyxell, B., \& Arlinger, S. (2001). Evaluation of a cognitive test battery in young and elderly normal-hearing and hearingimpaired persons. Journal of the American Academy of Audiology, 12(7), 357370.

Ivers, R.Q., Mitchell, P., \& Cumming, R.G. (1999). Sensory impairment and driving: The Blue Mountains Eye Study. American Journal of Public Health, $89(1), 85-87$.

Jansen, E., Holte, H., Jung, C., Kahmann, V., Moritz, K., Rietz, C., Rudinger, G., \& Weidemann, C. (2001). Ältere Menschen im künftigen Sicherheitssystem Straße/Fahrzeug/Mensch. [Senior citizens in the future safety system: street/vehicle/person]. Bremerhaven: Wirtschaftsverlag NW.

Jastak, J.F., \& Jastak, S.R. (1964). Short forms of the WAIS and WISC vocabulary subtests. Journal of Clinical Psychology, 20(2),167-199.

Johnston, B. (2008). Building better surveys - effective scales. Best practices. Available at http://www.surveygizmo.com/survey-blog/question-scale-length/. Accessed in August 2014.

Kane, M.J., \& Engle, R.W. (2002). The role of prefrontal cortex in workingmemory capacity, executive attention, and general fluid intelligence: an individual-differences perspective. Psychonomic Bulletin \& Review 9(4), 637671. 
Kennedy, Q., Taylor, J.L., Reade, G., \& Yesavage, J.A. (2010). Age and expertise effects in aviation decision making and flight control in a flight simulator. Aviation, Space, and Environmental Medicine, 81(5), 489.

Kipps, C.M., \& Hodges, J.R. (2005). Cognitive assessment for clinicians. Journal of Neurology Neurosurgery \& Psychiatry, 76(Suppl 1):22-30.

Kongsved, S.M., Basnov, M., Holm-Christensen, K., \& Hjollund, N.H. (2007). Response rate and completeness of questionnaires: a randomized study of internet versus paper-and-pencil versions. Journal of Medical Internet Research, 9(3), e25.

Köpke, S., Deubel, K., Engeln, A., \& Schlag, B. (1999). Mobilitätswahrnehmung und Selbstbild von älteren Autofahrern [Mobility awareness and self-image of older drivers]. In B. Schlag (Ed.), Empirische Verkehrspsychologie [Empirical traffic psychology]. Lengerich: Pabst Science Publishers; pp. 159-175.

Lehtonen, E., Dahlström, I., Hiltunen, H., \& Summala, H. (2012). On-road visual search and executive functions in elderly drivers. Paper presented at the International Conference on Traffic and Transport Psychology Groningen, Netherlands August 29-31.

Lewis-Evans, B. (2012). Testing models of driver behaviour. (Doctoral dissertation). University of Groningen.

Lewis-Evans, B., de Waard, D., \& Brookhuis, K. (2011). Speed maintenance under cognitive load - implications for theories of driver behaviour. Accidents Analysis and Prevention, 43(4), 1497-1507.

Li, K.Z. \& Lindenberger, U. (2002). Relations between aging sensory/sensorimotor and cognitive functions. Neuroscience and Biobehavioral Reviews, 26(7), 777783.

Li, Y., \& Perkins, A. (2007). The impact of technological developments on the daily life of the elderly. Technology in Society, 29(3), 361-368.

Lidestam, B., Lundqvist, A., \& Rönnberg, J. (2010). Concepts from research literature and practical assessment of risk awareness: the Swedish driving test from the perspective of cognitive psychology. Transportation Research Part F: Traffic Psychology and Behaviour, 13(6), 409-425.

Liang, K-Y., \& Zeger, S. (1986). Longitudinal data analysis using generalized linear models. Biometrika 73(1), 13-22.

Lin, F.R., Ferrucci, L., Metter, E.J., An, Y., Zonderman, A.B., \& Resnick, S.M. (2011). Hearing loss and cognition in The Baltimore Longitudinal Study of Aging. Neuropsychology, 25(6), 7637--70.

Lin, F.R., Metter, E.J., O’Brien, R.J., Resnick, S.M., Zonderman, A.B., \& Ferrucci, L. (2011). Hearing loss and incident dementia. Archives of Neurology, 68(2), 214-220.

Lin, F.R., Yaffe, K., Xia, J., Xue, Q.L., Harris, T.B., Purchase-Helzner, E., Satterfield, S., Ayonayon, H.N., Ferrucci, L., Simonsick, E.M. (2013). Hearing loss and cognitive decline in older adults. JAMA Internal Medicine, 173(4), 293-299. 
Lin, M.Y., Guttierrez, P.R., Stone, K.L., Yaffe, K., Ensrud, K.E., Fink, H.A., et al.; Study of Osteoporotic Fractures Research Group. (2004). Vision impairment and combined vision and hearing impairment predict cognitive and functional decline in older women. Journal of the American Geriatrics Society, 52, 19962002.

Lindenberger, U. \& Baltes, P.B. (1994). Sensory functioning and intelligence in old age: a strong connection. Psychology and Aging, 9, 339-355.

Lindenberger, U., Lövdén, M., Schellenbach, M., Li, S., \& Krüger, A. (2008). Psychological Principles of Successful Aging Technologies: A Mini-Review. Gerontology, 54, 59-68.

Ljung Aust, M. (2012). Improving the evaluation process for active safety functions - addressing key challenges in functional formative evaluation of advanced driver assistance systems. Thesis, Department of Applied Mechanics, Chalmers University of Technology, Gothenburg, Sweden.

Lundälv J. (2004). Self-reported experiences of incidents and injury events in traffic among hearing impaired people as pedestrians and cyclists. A follow-up study of mobility and use of hearing equipment. International Journal of Rehabilitation Research, 27(1):79-80.

Lunner, T. (2003). Cognitive function in relation to hearing aid use. International Journal of Audiology, 42 (Suppl 1), S49-S58.

Lyxell, B., Andersson, U., Borg, E., \& Ohlsson, I.S. (2003). Working-memory capacity and phonological processing in deafened adults and individuals with a severe hearing impairment. International Journal of Audiology, 42, 86-89.

Macintyre, S., Hiscock, R., Kearns, A., \& Ellaway, A. (2001). Housing tenure and car access: further exploration of the nature of their relation with health in a UK setting. Journal of Epidemiology and Community Health, 52, 657-664.

Magnet, W. (1992). Empirische Untersuchung zur Kompensationsfrage bei Gehörlosen Autofahrern. Eine Differentielle Analyse der Visuellen Wahrnehmung von Gehörlosen Kraftfahrern [Empirical examination of compensation made by deaf car drivers. A differential analysis of visual perception by deaf drivers]. Unpublished Dissertation, Universität Innsbruck, Innsbruck.

Marottoli, R., Mendes de Leon, C., Glass, T., Williams, C., Cooney, L.J., Berkman, L.F., \& Tinetti, M. (1997). Driving cessation and increased depressive symptoms: prospective evidence from the New Haven EPESE (Established Populations for Epidemiologic Studies of the Elderly). Journal of the American Geriatrics Society, 45, 202-206.

Mathers, C., Smith, A., \& Concha, M. (2003). Global burden of hearing loss in the year 2000. Working paper. Geneva: World Health Organization.

Mayr, U., Spieler, D.H., Kliegl, R. (2001). Aging and executive control. New York: Routledge.

McCloskey, L.W., Koepsell, T.D., Wolf, M.E., \& Buchner, D.M. (1994). Motorvehicle collision injuries and sensory impairments of older drivers. Age and Ageing, 23(4), 267-273. 
McDowd, J.M., \& Shaw, R.J. (2000). Attention and aging: a functional perspective. In: F.I.M. Craik, \& T.A. Salthouse (Eds.), The handbook of aging and cognition, 2nd ed. Mahwah, NJ: Erlbaum; pp. 221-292.

McEvoy, S.P., Stevenson, M.R., \& Woodward, M. (2006). The impact of driver distraction on road safety: results from a representative survey in two Australian states. Injury Prevention, 12, 242-247.

McHugh, M.L. (2009). The odds ratio: calculation, usage, and interpretation. Biochemia Medica, 19(2):120-126.

McKnight, A.J., \& Adams, B.B. (1970). Driver education task analysis. Vol.1: Task descriptions. Human Resources Research Organization, Alexandria, Virginia. Final Report, Contract No. FH 11-7336.

McRuer, D.T., Allen, R.W., Weir, D.H., \& Klein, R.H. (1977). New results in driver steering control models. Human Factors, 19, 381-397.

Michon, J.A. (1985). A critical view of driver behavior models: what do we know, what should we do? In L.A. Evans, \& R.C. Schwing (Eds.), Human behavior and traffic safety. New York: Plenum.

Mitzi M.S., \& Johnson, M. (1989). Age differences in decision making: a process methodology for examining strategic information processing. Journal of Gerontology, 45(2), 75-78.

Miyake, A., Friedman, N.P., Emerson, M.J., Witzki, A.H., \& Howerter, A. (2000). The unity and diversity of executive functions and their contributions to complex "frontal lobe" tasks: a latent variable analysis. Cognitive Psychology, 41, 49-100.

Miyake, A. \& Shah, P. (1999). Models of working memory. Cambridge, UK: Cambridge University Press.

Monsell, S. (1996). Control of mental processes. In V. Bruce (Ed.), Unsolved mysteries of the mind: tutorial essays in cognition. Hove, UK: Erlbaum; pp. 93-148.

Monterde-i-Bort, H. (2004). Factorial structure of recklessness: to what extent are older drivers different? Journal of Safety Research, 35, 329-335.

Moore, B.C. (1996). Perceptual consequences of cochlear hearing loss and their implications for the design of hearing aids. Ear and Hearing, 17(2), 133-161.

Moradi, S., Lidestam, B., Hällgren, M., \& Rönnberg, J. (2014). Gated auditory speech perception in elderly hearing aid users and elderly normal-hearing individuals: Effects of hearing impairment and cognitive capacity. Trends in Hearing, Jul 31;18. pii: 2331216514545406 . doi: 10.1177/2331216514545406.

Morris, N., \& Jones, D.M. (1990). Memory updating in working memory: the role of the central executive. British Journal of Psychology, 81, 111-121.

Mosteller, F. (1968). Association and estimation in contingency tables. Journal of the American Statistical Association, 63 (321), 1-28.

Mullen, N., Charlton, J., Devlin., A., \& Bédard, M. (2001). Simulator validity: behaviors observed on the simulator and on the road. In D.L. Fisher, M. Rizzo, J.K. Caird, \& J.D. Lee (Eds.), Driving simulation for engineering, medicine and psychology. Florida: Taylor and Francis. 
Nakeva von Mentzer, C. (2014). Rethinking Sound: Computer-assisted reading intervention with a phonics approach for deaf and hard of hearing children using cochlear implants or hearing aids. (Doctoral dissertation). Linköping: Linköping University Electronic Press.

Näätänen, R., \& Summala, H. (1974). A model for the role of motivational factors in drivers' decision-making. Accident Analysis \& Prevention, 6(3-4), 243-261.

Neisser, U. (1976). Cognition and reality: principles and implications of cognitive psychology: New York: W.H. Freeman.

Nilsson, L. (1993). Contributions and limitations of simulator studies to driver behaviour research. In A.A.M. Parkes, \& S. Franzen (Eds.), Driving future vehicles: Taylor \& Francis; pp. 401-407.

O’Brien, S. (2009) Eye tracking in translation process research: methodological challenges and solutions. In: I.M. Mees, F. Alves, \& S. Gopferich (Eds.), Methodology, technology and innovation in translation process research: a tribute to Arnt Lykke Jakobsen. Copenhagen Studies in Language, vol. 38. Copenhagen: Samfundslitteratur; pp. 251-266.

O’Donnell, R.D. \& Eggemeier, F.T. (1986). Workload assessment methodology. In K.R. Boff, L. Kaufman, \& J.P. Thomas (Eds.), Handbook of perception and human performance, vol. II, Cognitive processes and performance. New York: Wiley; pp. 42/1-42/49.

O'Hanlon, J.F. (1984). Driving performance under the influence of drugs: rationale for, and application of, a new test. British Journal of Clinical Pharmacology, $18,121 \mathrm{~S}-129 \mathrm{~S}$.

O’Hanlon, J.F., Haak, T.W., Blaauw, G.J. \& Riemersma, J.B.J. (1982). Diazepam impairs lateral position control in highway driving. Science, 217, 79-80.

Ohta, H., \& Komatsu, H. (1991). Speed perception in driving. Vision in vehicles, vol. III. Amsterdam: Elsevier Science Publishers; pp. 415-426.

Owsley, C., Ball, K., McGwin, G., Sloane, M.E., Roenker, D.L., White, M.F., et al. (1998). Visual processing impairment and risk of motor vehicle crash among older adults. Journal of the American Medical Association, 279(14), 10831088.

Parasuraman, R., \& Riley, V. (1997) Humans and automation: use, misuse, disuse, abuse. Human Factors, 39(2), 230-253.

Pearson, J.D., Morrell, C.H., Gordon-Salant, S., Brant, L.J., Metter, E.J., Klein, L.L., \& Fozard, J.L. (1995). Gender differences in a longitudinal-study of ageassociated hearing-loss. Journal of the Acoustical Society of America, 97(2), 1196-1205.

Pelli, D.G., Robson, J.G., \& Wilkins, A.J. (1988). The design of a new letter chart for measuring contrast sensitivity. Clinical Vision Sciences, 2, 187-199.

Peters, B., \& Nielsen, B. (2007). A strategy aiming to compensate degraded abilities among elderly drivers. 11th International Conference on Mobility and Transport for Elderly and Disabled Persons, Montreal, Canada.

Peters, B., \& Nilsson, L. (2006). Modelling the driver in control. In P. Cacciabue (Ed.), Modelling driver behaviour in automotive environments - critical issues in driver interactions with intelligent transport systems. London: Springer. 
Peters C.A., Potter J.F., \& Scholer S.G. (1988). Hearing impairment as a predictor of cognitive decline in dementia. Journal of the American Geriatriatrics Society, 36(11):981-986.

Phillips, N.A., \& Lesperance, D. (2003). Breaking the waves: age differences in electrical brain activity when reading text with distractors. Psychology and Aging, 18(1), 126-139.

Picard, M., Girard, S.A., Courteau, M., Leroux, T., Larocque, R., Turcotte, F., et al. (2008). Could driving safety be compromised by noise exposure at work and noise-induced hearing loss? Traffic Injury Prevention, 9(5), 489-499.

Pichora-Fuller, M.K., \& Singh, G. (2006). Effects of age on auditory and cognitive processing: implications for hearing aid fitting and audiologic rehabilitation. Trends in Amplification, 10(1), 29-59.

Rajalin, S., Hassel, S.O., \& Summala, H. (1997). Close-following drivers on twolane highways. Accident Analysis \& Prevention, 29(6), 723-729.

Ranney, T. (1994) Models of driving behavior: a review of their evolution. Accident Analysis \& Prevention, 26(6), 733-750.

Pohlmann, S. \& Traenkle, U. (1994). Orientation in road traffic. Age-related differences using an in-vehicle navigation system and a conventional map. Accident Analysis \& Prevention, 26, 689-702.

Reitan, R. (1986). Trail making test. Manual for administration and scoring. Tuscon, AZ: Neuropsychological Laboratory.

Repovs, G. \& Baddeley, A. (2006). The multi-component model of working memory: explorations in experimental cognitive psychology. Neuroscience Special Issue, 139, 5-21.

Riediger, M., Li, S. C., \& Lindenberger, U. (2006). Selection, optimization, and compensation as developmental mechanisms of adaptive resource allocation: Review and preview. Handbook of the psychology of aging, 6, 289-313.

Rimmer, J. (2006). Use of the ICF in identifying factors that impact participation in physical abilities/rehabilitation among people with disabilities. Disability and Rehabilitation, 28, 1087-1095.

Rimmö, P.-A., \& Hakamies-Blomqvist, L. (2002). Older drivers' aberrant driving behaviour, impaired activity, and health as reasons for self-imposed driving limitations. Transportation Research Part F: Traffic Psychology and Behaviour, 5, 345-360.

Risacher, S.L., Wudunn, D., Pepin, S.M., MaGee, T.R., McDonald, B.C., Flashman, L.A., et al. (2013). Visual contrast sensitivity in Alzheimer's disease, mild cognitive impairment, and older adults with cognitive complaints. Neurobiology of Aging, 34(4):1133-1144.

Roebuck, J. (1979). When does old age begin? The evolution of the English definition. Journal of Social History, 12(3):416-428.

Roth, T.N., Hanebuth, D., \& Probst, R. (2001). Prevalence of age-related hearing loss in Europe: a review. European Archives of Oto-Rhino-Laryngology, 268(8), 1101-1107. 
Rothe, J.P. (1990). The safety of elderly drivers. London: Transaction Publishers.

Rouse, W. B., Edwards, S. L. \& Hammer, J. M. (1993). Modelling the dynamics of mental workload and human performance in complex systems. IEEE transactions on systems, man, and cybernetics, 23, 1662-1671.

Rumar, K. (1988). Collective risk but individual safety. Ergonomics, 31(4), $507-$ 518.

Rönnberg, J. (1990). Cognitive and communicative function: the effects of chronological age and "handicap age". European Journal of Cognitive Psychology, 2, 253-273.

Rönnberg, J., Danielsson, H., Rudner, M., Arlinger, S., Sternang, O., Wahlin, A., \& Nilsson, L. G. (2011). Hearing loss is negatively related to episodic and semantic long-term memory but not to short-term memory. Journal of Speech Language and Hearing Research, 54(2), 705-726.

Rönnlund, M., Nyberg, L., Bäckman, L., \& Nilsson, L. G. (2005). Stability, growth, and decline in adult life span development of declarative memory: crosssectional and longitudinal data from a population based study. Psychology and Aging, 20(1), 3-18.

Salthouse, T.A., Babcock, R.L. (1991). Decomposing adult age-differences in working memory. Developmental Psychology, 27(5), 763-776.

Salthouse, T.A. (1996). The processing-speed theory of adult age differences in cognition. Psychological Review. 103: 403-428.

Salvucci D.D. (2006) Modeling Driver Behavior in a Cognitive Architecture. Human Factors, 48 (2), 362-380

Sandberg, U. (2003). The multi-coincidence peak around $1000 \mathrm{~Hz}$ in tyre/road noise spectra. Paper presented at the Euronoise. May, 19-21, Naples.

Saremi, A., \& Stenfelt, S. (2013). Effect of metabolic presbyacusis on cochlear responses: a simulation approach using a physiologically-based model. Journal of the Acoustic Society of America, 134(4), 2833-2851.

Schmolz, W. (1987). Die Bedeutung des Hoehrens im Verkehr. [The effect of hearing in traffic]. Polizei Verkehr Technik, 32(11), 379-380.

Schneider, B. A., Pichora-Fuller, M. K., \& Daneman, M. (2010). Effects of senescent changes in audition and cognition on spoken language comprehension. In S. Gordon-Salant, R.R. Frisina, R.R. Fay, \& A. Popper(Eds.), The aging auditory system. New York: Springer.

Schneider, J., Gopinath, B., Karpa, M.J., McMahon, C.M., Rochtchina, E., Leeder, S.R., \& Mitchell, P. (2010). Hearing loss impacts on the use of community and informal supports. Age and Ageing, 39(4), 458-464.

Selander, H., Lee, H.C., Johansson, K., \& Falkmer, T. (2011). Older drivers: onroad and off-road test results. Accidents Analysis and Prevention, 43(4). 13481354.

Shinar, D. (2007). Traffic safety and human behavior. Oxford: Elsevier.

Sirén, A., \& Hakamies-Blomqvist, L. (2004). Private car as the grand equaliser? Demographic factors and mobility in Finnish men and women aged 65+. Transportation Research Part F: Traffic Psychology and Behaviour, 7(2), 107118. 
Sirén, A. \& Hakamies-Blomqvist, L. (2009). Mobility and well-being in old age. Topics in Geriatric Rehabilitation, 25(1), 3-11.

Sternberg, S. (1966). High-speed scanning in human memory. Science, 153, 652654.

Stevens, G., Flaxman, S., Brunskill, E., Mascarenhas, M., Mathers, CD., \& Finucane, M. (2013). Global and regional hearing impairment prevalence: an analysis of 42 studies in 29 countries. European Journal of Public Health, 23(1), 146-152.

Sullivan, K.A., Smith, S.S., Horswill, M.S., \& Lurie-Beck, J.K. (2011). Older adults' safety perceptions of driving situations: towards a new driving selfregulation scale. Accident Analysis \& Prevention, 43(3), 1003-1009.

Summala, H. (2005). Traffic psychology theories: towards understanding driving behaviour and safety efforts. In G. Underwood (Ed.), Traffic and Transport Psychology. Amsterdam: Elsevier; pp. 383-394,

Summala, H. (2007). Towards understanding motivational and emotional factors in driver behaviour: Comfort through satisficing. In C. Cacciabue (Ed.), Modelling Driver Behaviour in Automotive Environments. London: Springer; pp. 189-207.

Summala, H., Etholén, T., Leino, N., Niskakangas, M., Laine, M. \& Saarinen, S. (2008). FR-TMT: visuospatial (working) memory in a computerized TrailMaking test. Poster presented at the Psykologia 2008 Congress, August 20-22, Helsinki.

Teng EL, Chui HC. (1987) The Modified Mini-Mental State (3MS) Examination. Journal of Clinical Psychiatry, 48(8):314-318.

Thomas, P.D., Hunt, W.C., Garry, P.J., Hood, R.B., Goodwin, J.M. \& Goodwin, J.S. (1983). Hearing acuity in a healthy elderly population: effects on emotional, cognitive, and social status. Journal of Gerontology, 38, 321-325.

Tun, P.A., McCoy, S., \& Wingfield, A. (2009) Aging, hearing acuity, and the attentional costs of effortful listening. Psychology and Aging, 24(3), 761-766.

Vaa, T. (2003). Survival or deviance? A model for driver behaviour. (TOI report 666/2003). Oslo: Institute of Transport Economics.

Vaa, T. (2007). Modelling driver behaviour on basis of emotions and feelings: intelligent transport systems and behavioural adaptations. In C. Cacciabue (Ed.), Modelling driver behaviour in automotive environments. London: Springer; pp. 208-232.

Vaa, T. (2011). Proposing a driver behaviour model based on emotions and feelings: exploring the boundaries of perception and learning. In M. Regan, T. Victor \& J. Lee (Eds.), Driver distraction and inattention: advances in research and countermeasures. Farnham, UK: Ashgate Publishing.

Vaa, T., Glad, A., \& Sagberg, F. (2000). Developing a model of driver behaviour: introductory working papers. (TOI report 503/2000). Oslo: Institute of Transport Economics.

Valentijn S.A., van Boxtel M.P., van Hooren S.A., Bosma H., Beckers H.J., Ponds R.W., \& Jolles J. (2005). Change in sensory functioning predicts change in cognitive functioning: results from a 6-year follow-up in the Maastricht Aging Study. Journal of the American Geriatrics Society 53(3),374-380. 
van der Linden, M., Brédart, S., \& Beerten, A. (1994). Age-related differences in updating working memory. British Journal of Psychology, 85, 145-152.

van der Linden, M., Hupet, M., Feyereisen, P., Schelstraete, M., Bestgen, M., Bruyer, G.L., Abdessadek, E.A., \& Seron., X. (1999). Cognitive mediators of age-related differences in language comprehension and verbal processing. Aging, Neuropsychology, and Cognition, 6, 32-55.

van Erp, J.B.F., \& van Veen, H.A.H.C. (2004). Vibrotactile in-vehicle navigation system. Transportation Research Part F: Traffic Psychology and Behaviour, 7, 247-256.

Verhaeghen, P., Cerella, J., Bopp, K.L., \& Basak, C. (2005). Aging and varieties of cognitive control: a review of meta-analyses on resistance to interference, coordination, and task switching, and experimental exploration of agesensitivity in the newly identified process of focus switching. In: R.W. Engle, G. Sedek, U. Von Hecker, \& D.N. McIntosh (Eds), Cognitive limitations in aging and psychopathology. New York: Cambridge University Press; pp. 160189.

Verhaeghen, P., Steitz, D.W., Sliwinski, M.J., \& Cerella, J. (2003). Aging and dualtask performance: a meta-analysis. Psychology and Aging, 18, 443-460.

Vreeken, H.L., van Rens, G., Knol, D.L., van Reijen, N.A., Kramer, S.E., Festen, M.J., \& van Nispen, R.M.A. (2013). Dual sensory loss: a major age-related increase of comorbid hearing loss and hearing aid ownership in visually impaired adults. Geriatrics and Gerontology International. Available at http://www.biomedcentral.com/1471-2318/13/84. Accessed on September 25, 2014.

Wallhagen, M. I. (2010). The stigma of hearing loss. Gerontologist, 50(1), 66-75.

Wechsler D. (1981). Manual for the Wechsler Adult Intelligence Scale-Revised. New York: Psychological Corp.

Wickens, C. D., \& Hollands, J. G. (1999). Engineering Psychology and Human Performance (3nd ed.). New York: Harper Collins.

Wilson, G.F. \& Eggemeier, F.T. (1991). Psychophysiological assessment of workload in multi-task environments. In D.L. Damos (Ed.), Multiple-task performance. London: Taylor \& Francis; pp. 329-360.

World Health Organization (WHO). (2001). International Classification of Functioning, Disability and Health (ICF). Geneva: World Health Organization.

Wu, Y.H., Aksan, N., Rizzo, M., Stangl, E., Zhang, X., \& Bentler, R. (2014). Measuring listening effort: driving simulator versus simple dual-task paradigm. Ear and Hearing, doi: 10.1097/AUD.0000000000000079.

Wu, Y.H., Stangl, E., Bentler, R., \& Stanziola, R.W. (2013). The effect of hearing aid technologies on listening in an automobile. Journal of Clinical Experimental Neuropsychology of the American Academy of Audiology, 24(6), 474-485. 
Papers I-IV 



\section{Papers}

The articles associated with this thesis have been removed for copyright reasons. For more details about these see:

http://urn.kb.se/resolve?urn=urn:nbn:se:liu:diva-111933 



\section{Studies from the Swedish Institute for Disability Research}

1. Varieties of reading disability

Stefan Gustafson

ISBN 91-7219-867-2, 2000

2. Cognitive functions in drivers with brain injury - anticipation and adaptation Anna Lundqvist

ISBN 91-7219-967-9, 2001

3. Cognitive deafness

Ulf Andersson

ISBN 91-7373-029-7, 2001

4. Att lära sig leva med förvärvad hörselnedsättning sett ur par-perspektiv

Carin Fredriksson

ISBN 91-7373-105-6, 2001

5. Signs, Symptoms, and Disability Related to the Musculo-Skeletal System Gunnar Lundberg

ISBN 91-7373-160-9, 2002

6. Participation - Ideology and Everyday Life

Anette Kjellberg

ISBN 91-7373-371-7, 2002

7. Föräldrar med funktionshinder - om barn, föräldraskap och familjeliv

Marie Gustavsson Holmström

ISBN 91-7203-500-5, 2002

8. Active wheelchair use in daily life

Kersti Samuelsson

ISBN 91-7373-196-X, 2002

9. Två kön eller inget alls. Politiska intentioner och vardagslivets realiteter i den arbetslivsinriktade rehabiliteringen

Marie Jansson

ISBN 91-7373-568-X, 2003 
10. Audiological and cognitive long-term sequelae from closed head injury Per-Olof Bergemalm

ISBN 91-7668-384-2, 2004

11. Att vara i särklass - om delaktighet och utanförskap i gymnasiesärskolan Martin Molin

ISBN 91-85295-46-9, 2004

12. Rättvis idrottsundervisning för elever med rörelsehinder - dilemma kring omfördelning och erkännande

Kajsa Jerlinder

Licentiate Degree, 2005

13. Hearing impairment and deafness. Genetic and environmental factors interactions - consequences. A clinical audiological approach

Per-Inge Carlsson

ISBN 91-7668-426-1, 2005

14. Hearing and cognition in speech comprehension. Methods and applications Mathias Hällgren

ISBN 91-85297-93-3, 2005

15. Living with deteriorating and hereditary disease: experiences over ten years of persons with muscular dystrophy and their next of kin

Katrin Boström

ISBN 91-7668-427-x, 2005

16. Disease and disability in early rheumatoid arthritis

Ingrid Thyberg

ISBN 91-85299-16-2, 2005

17. "Varför får jag icke följa med dit fram?" Medborgarskapet och den offentliga debatten om dövstumma och blinda 1860-1914

Staffan Bengtsson

ISBN 91-85457-06-X, 2005

18. Modalities of Mind. Modality-specific and nonmodality-specific aspects of working memory for sign and speech

Mary Rudner

ISBN 91-85457-10-8, 2005 
19. Facing the Illusion Piece by Piece. Face recognition for persons with learning disability

Henrik Danielsson

ISBN 91-85497-09-6, 2006

20. Vuxna med förvärvad traumatisk hjärnskada - omställningsprocesser och konsekvenser i vardagslivet. En studie av femton personers upplevelser och erfarenheter av att leva med förvärvad traumatisk hjärnskada

Thomas Strandberg

ISBN 91-7668-498-9, 2006

21. Nycklar till kommunikation. Kommunikation mellan vuxna personer med grav förvärvad hjärnskada och personernas närstående, anhöriga och personal

Pia Käcker

ISBN 978-91-85715-88-6, 2007

22. ”Aspergern, det är jag”. En intervjustudie om att leva med Asperger syndrom

Gunvor Larsson Abbad

ISBN 978-91-85831-43-2, 2007

23. Sounds of silence - Phonological awareness and written language in children with and without speech

Janna Ferreira

ISBN 978-91-85895-74-8, 2007

24. Postponed Plans: Prospective Memory and Intellectual Disability

Anna Levén

ISBN 978-91-85895-57-1, 2007

25. Consequences of brain tumours from the perspective of the patients and of their next of kin

Tanja Edvardsson

ISBN 978-91-7668-572-3, 2008

26. Impact on participation and service for persons with deafblindness

Kerstin Möller

ISBN 978-91-7668-595-2, 2008

27. Approaches to Audiological Rehabilitation with Hearing Aids: studies on prefitting strategies and assessment of outcomes

Marie Öberg

ISBN 978-91-7393-828-0, 2008 
28. Social Interaction and Participation in Activities of Everyday Life Among Persons with Schizophrenia

Maria Yilmaz

Licentiate Degree, 2009

29. Focus on Chronic Disease through Different Lenses of Expertise

Towards Implementation of Patient-Focused

Decision Support Preventing Disability:

The example of Early Rheumatoid Arthritis

Örjan Dahlström

ISBN 978-91-7393-613-2, 2009

30. Children with Cochlear Implants: Cognition and Reading Ability

Malin Wass

ISBN: 978-91-7393-487-9, 2009

31. Restricted participation:

Unaccompanied children in interpreter-mediated asylum hearings in Sweden

Olga Keselman

ISBN: 978-91-7393-499-2, 2009

32. Deaf people and labour market in Sweden.

Education - Employment - Economy

Emelie Rydberg

ISBN: 978-91-7668-725-3, 2010

33. Social rättvisa i inkluderande idrottsundervisning

för elever med rörelsehinder - en utopi?

Kajsa Jerlinder

ISBN: 978-91-7668-726-0, 2010

34. Erfarenheter av rehabiliteringsprocessen mot ett arbetsliv

- brukarens och de professionellas perspektiv

Helene Hillborg

ISBN: 978-91-7668-741-3, 2010

35. Knowing me, knowing you - Mentalization abilities of children who use augmentative and alternative communication

Annette Sundqvist

ISBN: 978-91-7393-316-2, 2010 
36. Lärare, socialsekreterare och barn som far illa - om sociala representationer och interprofessionell samverkan

Per Germundsson

ISBN: 978-91-7668-787-1, 2011

37. Fats in Mind

Effects of Omega-3 Fatty Acids on Cognition and Behaviour in Childhood

Ulrika Birberg Thornberg

ISBN: 978-91-7393-164-9, 2011

38. ”Jobbet är kommunikation”

Om användning av arbetshjälpmedel för personer med hörselnedsättning

Sif Bjarnason

Licentiate Degree. ISBN: 978-91-7668-835-9, 2011

39. Applying the ICF-CY to identify everyday life situations of children and youth with disabilities

Margareta Adolfsson

ISBN: 978-91-628-8342-3, 2011

40. Tinnitus - an acceptance-based approach

Vendela Zetterqvist

ISBN: 978-91-7393-040-6, 2011

41. Applicability of the ICF-CY to describe functioning and environment of children with disabilities

Nina Klang

ISBN: 978-91-7668-864-9, 2012

42. Bringing more to participation

Participation in school activities of persons with Disability within the framework of the International Classification of Functioning, Disability and Health for Children and Youth (ICF-CY)

Gregor Maxwell

ISBN: 978-91-628-8484-0, 2012

43. From Eye to Us.

Prerequisites for and levels of participation in mainstream school of persons with Autism Spectrum Conditions

Marita Falkmer

ISBN: 978-91-637-2091-8, 2013 
44. Otosclerosis, clinical long-term perspectives

Ylva Dahlin-Redfors

ISBN 978-91-628-8617-2, 2013

45. Tinnitus in Context - A Contemporary Contextual Behavioral Approach Hugo Hesser

ISBN 978-91-7519-701-2, 2013

46. Hearing and middle ear status in children and young adults with cleft palate Traci Flynn

ISBN 978-91-628-8645-5, 2013

47. Utrymme för deltagande, beslutsprocesser $\mathbf{i}$ möten mellan patienter med ospecifika ländryggsbesvär och sjukgymnaster i primär vård

Iréne Josephson

ISBN 42-978-91-85835-41-6, 2013

48. Man vill ju klara sig själv” Studievardagen för studenter med Asperger syndrom i högre studier

Ann Simmeborn Fleischer

ISBN 978-91-628-8681-3, 2013

49. Cognitive erosion and its implications in Alzheimer's disease

Selina Mårdh

ISBN 978-91-7519-621-1, 2013

50. Hörselscreening av en population med utvecklingsstörning

Utvärdering av psykoakustisk testmetod och av OAE-registrering som komplementär metod

Eva Andersson

Licentiate Degree. ISBN 978-91-7519-616-9, 2013

51. Skolformens komplexitet - elevers erfarenheter av skolvardag och tillhörighet i gymnasiesärskolan

Therése Mineur

ISBN 978-91-7668-951-6, 2013

52. Evaluating the process of change:

Studies on patient journey, hearing disability acceptance and stages-of-change

Vinaya Kumar Channapatna Manchaiah

ISBN 978-91-7519-534-6, 2013 
53. Cognition in hearing aid users: Memory for everyday speech

Hoi Ning (Elaine) $\mathrm{Ng}$

ISBN 978-91-7519-494-3, 2013

54. Representing sounds and spellings Phonological decline and compensatory working memory in acquired hearing impairment

Elisabet Classon

ISBN 978-91-7519-500-1, 2013

55. Assessment of participation in people with a mild intellectual disability

Patrik Arvidsson

ISBN 978-91-7668-974-5, 2013

56. Barnperspektiv i barnavårdsutredningar - med barns hälsa och barns upplevelser i fokus

Elin Hultman

ISBN 978-91-7519-457-8, 2013

57. Internet Interventions for Hearing Loss

Examining rehabilitation Self-report measures and Internet use in hearing-aid users

Elisabet Sundewall Thorén

ISBN 978-91-7519-423-3, 2014

58. Exploring Cognitive Spare Capacity: Executive Processing of Degraded Speech Sushmit Mishra

ISBN 978-91-7519-386-1, 2014

59. Supported employment i en svensk kontext - förutsättningar när personer med funktionsnedsättning når, får och behåller ett arbete

Johanna Gustafsson

ISBN 978-91-7529-012-6, 2014

60. Effects of Specific Cochlear Pathologies on the Auditory Functions:

Modelling, Simulations and Clinical Implications

Amin Saremi

ISBN 978-91-7519-365-6, 2014 
61. Children with profound intellectual and multiple disabilities and their participation in family activities

Anna Karin Axelsson

ISBN 978-91-85835-48-5, 2014

62. Lexical and Semantic Development in Children With Cochlear Implants

Ulrika Löfkvist

ISBN 978-91-7549-546-0, 2014

63. Rethinking sound. Computer-assisted reading intervention with a phonics approach for deaf and hard of hearing children using cochlear implants or hearing aids

Cecilia Nakeva von Mentzer

ISBN 978-91-7519-270-3, 2014

64. Assessing cognitive spare capacity as a measure of listening effort using the Auditory Inference Span Test

Niklas Rönnberg

ISBN 978-91-7519-267-3, 2014

65. Employees with Aided Hearing Impairment: An Interdisciplinary Perspective Håkan Hua

ISBN 978-91-7519-240-6, 2014

66. Prosthetic and Orthotic Services in Developing Countries

Lina Magnusson

ISBN 978-91-85835-55-3, 2014

67. Dealing with digits - Arithmetic, memory and phonology in deaf signers Josefine Andin

ISBN: 978-91-7519-235-2, 2014

68. Time is of the essence in speech recognition: Get it fast or think about it Shahram Moradi

ISBN: 978-91-7519-188-1, 2014 